\title{
20. THERMAL REGIME OF THE CHILE TRIPLE JUNCTION: CONSTRAINTS PROVIDED BY DOWNHOLE TEMPERATURE MEASUREMENTS AND DISTRIBUTION OF GAS HYDRATE ${ }^{1}$
}

\author{
K.M. Brown ${ }^{2}$ and N.L. Bangs ${ }^{3}$
}

\begin{abstract}
The combination of logging, and downhole temperature measurements at Site 859 (and to a lesser extent Site 861) suggest that the composition of the hydrates forming the regionally distributed bottom simulating reflector in the Chile Triple Junction region may be close to a seawater/methane composition. Direct calibration of the pressure-temperature condition at the BSR has allowed us to extend our downhole measurements laterally. We focus much of our discussion in this paper on the transect of holes (Site 859,860 , and 861 ) along seismic Line 745 . This transect characterizes the thermal regime existing in the wedge just prior to ridge subduction. Temperature gradients and heat flows were found to be lower, and the temperature profiles dominantly linear, in the older regions of the wedge (i.e., Site 861). In contrast, higher temperature gradients and highly non-linear profiles are found at the toe of the wedge (i.e., Sites 859 and 863). The major regional increase in the geothermal gradient and heat flow towards the toe of the wedge is also clearly shown by the shallowing in depth to the BSR across the transect. This is proposed to stem from a combination of the greater heat input to the base of the toe of the wedge, due to its closer proximity to the subducting spreading ridge, and the lateral expulsion of warm fluids. The laterally expelled fluids cause disturbances in both temperature and pore water chemistry profiles and discrepancies in shallow and deep heat flow estimates. Hydraulic disturbances are particularly evident within $5 \mathrm{~km}$ of the toe of the wedge where much of the fluid expulsion is proposed to be focused. Near the toe, the hydrogeologic system is also spatially heterogeneous, may be effected by both wedge and oceanic basement components, and appears to change episodically on a short time scale. This makes quantitative estimates of heat budgets difficult to constrain. It is possible that a significant amount of the heat input to the base of the wedge from the oceanic basement is subsquently expelled at the accretionary toe; carried there by the fluids migrating along fault zones.
\end{abstract}

\section{INTRODUCTION}

\section{Tectonic and Thermal Environment}

The Chile Triple Junction (CTJ) is one of only two world-wide examples where an oceanic/transform spreading axis is currently being subducted beneath continental lithosphere. Ridge subduction has, however, formed a part of the history of most of the western Pacific subduction zones and the study of this currently active system can be used to constrain on land investigations of the effects of these paleo-ridge subduction events. Subduction of the ridge beneath South America began in the south near Tierra del Fuego and has migrated north to its current position near the Taitao peninsula. Hiatuses in ridge subduction occur during the underthrusting of fracture zones that offset the ridge axis (Cande et al., 1987). Ocean Drilling Program (ODP) Leg 141 studied the thermal structure of the portion of the wedge just to the north of the triple junction. This section is currently overthrusting the segment of the Chile oceanic spreading center situated between the Darwin and Taitao fracture zones from $45^{\circ} 45^{\prime}$ to $46^{\circ} 18^{\prime} \mathrm{S}$ (Fig. 1).

Significant accretion and tectonic thickening has not occurred south of the Darwin Fracture Zone (DFZ) in the region drilled during ODP Leg 141 since Pleistocene times (Fig. 1). Here it seems the thin cover of sediments $(\sim 100 \mathrm{~m})$ on the subducted plate bypass the toe and become thrust deep beneath the wedge. Indeed, substantial subduction erosion is probably occurring in this region (Behrmann et al., in press.; Cande, et al., 1987). The transect of drilling sites (Sites 859 , 860 , and 861) provides a characterization of the tectonic environment just prior to spreading ridge subduction and are located within the

\footnotetext{
'Lewis, S.D., Behrmann, J.H., Musgrave, R.J., and Cande, S.C. (Eds.), 1995. Proc. ODP, Sci. Results, 141: College Station. TX (Ocean Drilling Program).

Scripps Institution of Oceanography, University of California at San Diego, La Jolla, CA 92093-0220. U.S.A.

${ }^{3}$ Institute for Geophysics, University of Texas at Austin, Austin, TX 78759-8397.
}

accretionary wedge predominantly along Conrad Line 745 (Fig. 1). The line is approximately $10 \mathrm{~km}$ south of the DFZ and $18 \mathrm{~km}$ north of the present triple junction location. On Line 745 the axis of the spreading center lies $\sim 5 \mathrm{~km}$ west of the accretionary toe and is expected to be thrust beneath the toe of the wedge in 100 to $200 \mathrm{k} . \mathrm{y}$. Very high heat flows (greatly in excess of $250 \mathrm{mWm}^{-2}$ ) were expected from this practically zero age crust. In contrast, Leg 141 Site 863, located $18 \mathrm{~km}$ south of Line 745 , is drilled into the toe of the accretionary wedge, directly over the subducting spreading center (Fig. 1).

As will be shown herein, there is evidence that the heat flow data obtained during ODP Leg 141 are strongly influenced by fluid migration. Oceanic spreading centers are noted for their generally high heat flows and vigorous convective hydrogeologic systems that are driven by the cooling of the new basaltic material (e.g., Sclater et al., 1980). Accretionary wedges also are hydrogeologically active regions. In accretionary wedges, warm fluids having exotic geochemistries commonly migrate laterally long distances along faults as they are expelled out of the deep regions of the subducted sedimentary pile (Carson et al., 1990; Gieskes et al., 1990; Moore et al., 1991). The common association of thermal and geochemical anomalies with faults suggests that faults form preferred pathways due to their higher permeabilities (Moore et al., 1991). Our data indicates that the progressive underthrusting of a vigorously convective hydrothermal system, associated with the spreading ridge beneath a hydrogeologically active accretionary wedge, produces a complex, dynamic thermal, and hydrogeologic regime in the Leg 141 region.

\section{Gas Hydrates}

Bottom Simulating Reflectors (BSRs) are frequently seen in seismic sections several hundred meters below the seafloor. The BSR is taken to mark the base of the pressure temperature (PT) stability field for methane clathrate hydrate because BSRs are thought to relate to the impedance contrast between hydrate-bearing and hydrate-free sediments, which lie correspondingly above and below the hydrate stability field (Bangs et al., 1993; Hyndman et al., 1992; Kvenvolden, 


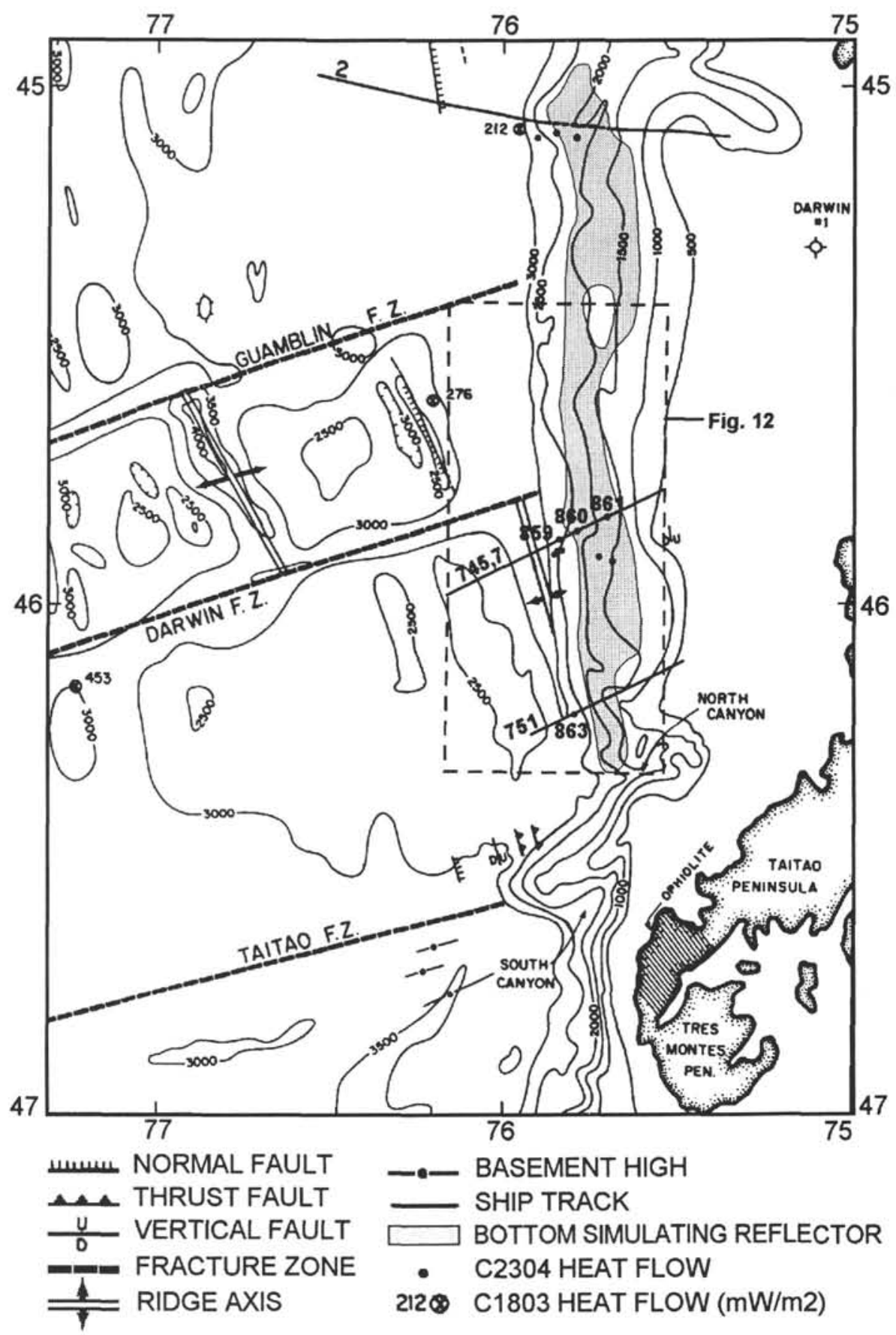

Figure 1. A map of the main tectonic elements and BSR distribution in the Chile Triple Junction region.

1985; Kvenvolden and Barnard, 1982). With accurate calibration of temperature/pressure conditions at the base of the hydrate stability field, the BSR can be used to infer these conditions at depth. The greater sensitivity of the hydrate stability field to temperature rather than pressure (Hyndman et al., 1992; Sloan, 1990) makes the BSR a particularly good indicator of the regional thermal regime. BSRs are commonly observed in the lower to middle regions of the continental slope (Kvenvolden, 1985; Kvenvolden and Barnard, 1982). They occur extensively in the upper regions of the accreted sediments and slope sediments in the CTJ region and provide temperature data in regions surrounding the drill sites.

Laboratory data defining the P-T stability fields are available for various possible hydrate compositions that can form in sediments (Sloan, 1990; Fig. 2). The hydrate composition is, however, generally poorly known in a given environment or region. Unfortunately, salinity, $\mathrm{CO}_{2}$, and the presence of various higher order hydrocarbons all affect the stability field of the hydrate to varying degrees (Fig. 2), and uncertainty in the hydrate composition introduces uncertainty in the P-T calibrations. Hyndman et al. (1992) presented an estimated position of the seawater curve in the stability region of interest based on extrapolation from rather limited information at lower pressures. The estimated seawater curve lies $\sim 1.5^{\circ} \mathrm{C}$ below that of the pure water methane curve. However, given the lack of prime data, Hyndman et al. considered the likely error in the position of this curve to be $\pm 1^{\circ} \mathrm{C}$. One of the primary aims of Leg 141 was to calibrate directly the temperature and depth of the BSR in the CTJ region using downhole temperature measurements and sonic logging. These measurements were made successfully at Sites 859 and 861 . 


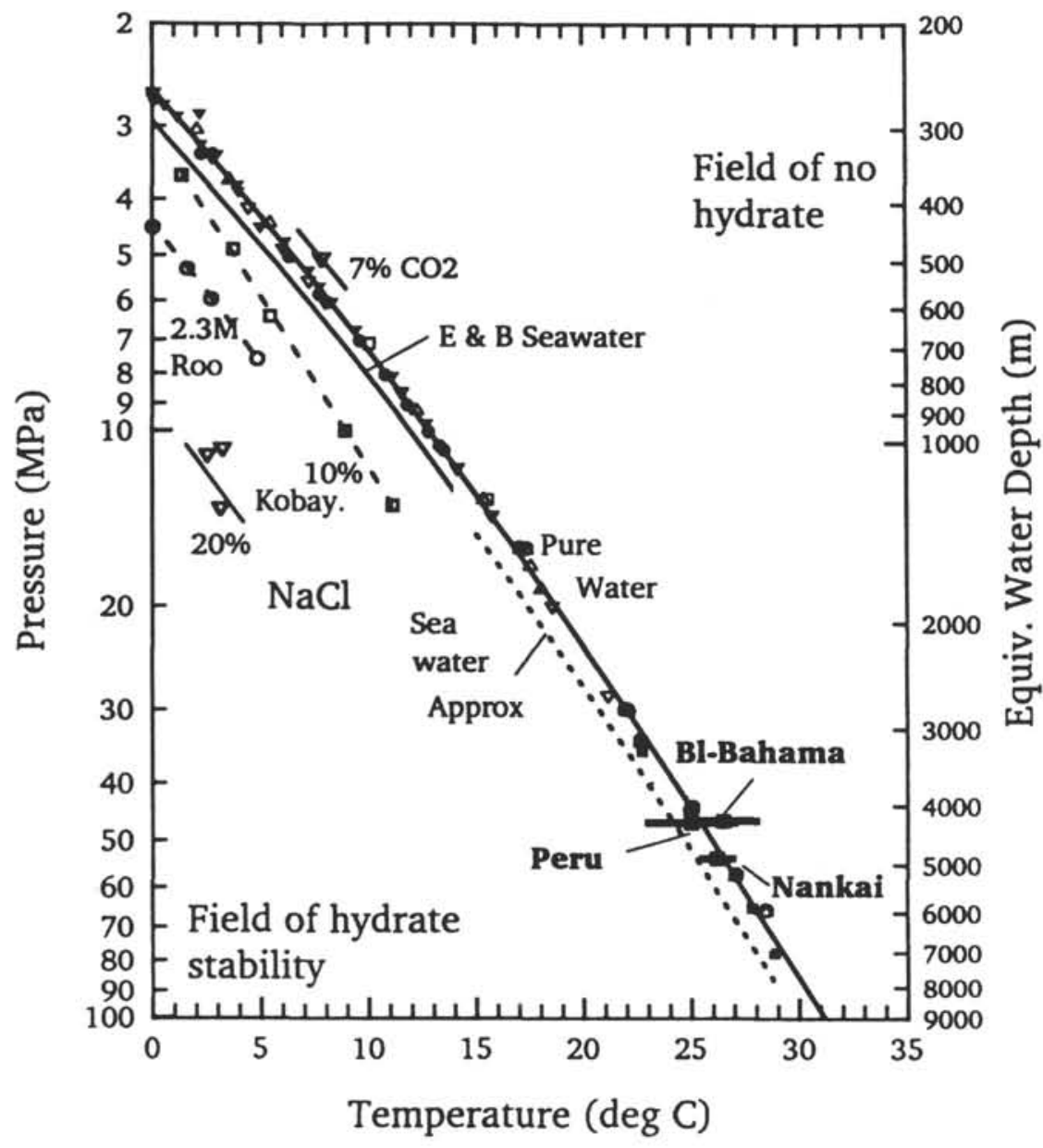

Figure 2. Previous estimates of Hyndman et al. (1992) of the pressure and temperature conditions at the level of the seismic BSR plotted against laboratory data (from a compilation of Sloan, 1989) for the hydrate stability fields.

\section{ADARA and WSTP Temperature Tools}

The downhole temperature data were obtained during Leg 141 drilling from the water-sampling temperature probe (WSTP), the advanced piston core temperature coring shoe (ADARA), and the Lamont temperature logging tool (TLT). Only a brief description of the WSTP and ADARA tools is given here. More complete descriptions can be found in the explanatory notes (Behrmann, Lewis, Musgrave, et al., 1992). The TLT is described in some detail in Sawyer et al. (this volume).

The WSTP and ADARA tools are designed to collect essentially pristine formation temperature unaffected by drilling disturbance. This is possible because the tool is pushed into the formation at the bottom of the hole in advance of drilling. The WSTP is a self-contained wireline probe that is lowered to the base of the hole and latched into the drill bit so that the tip of the probe extends approximately $1.1 \mathrm{~m}$ ahead of the bit. The temperature is estimated from the thermal decay curve that is generate when the tool is inserted (see fitted decay curves in Behrmann, Lewis, Musgrave, et al., 1992). The WSTP tool comes in two configurations; the first configuration allows formation water to be collected along with temperature; the second is a temperatureprobe-only configuration. All the WSTP temperature decay profiles are shown in the ODP Leg 141 initial reports volume (Behrmann, Lewis, Musgrave, et al., 1992) a few representative examples are also shown here, particularly for Site 859 were the thermal profile is particularly complex and difficult to interpret.

The ADARA Tool is contained within the piston coring shoe. During normal operation, the piston corer is fired into the sediments up to $10 \mathrm{~m}$ in front of the bit. The extraction of the piston corer is delayed for $\sim 10 \mathrm{~min}$. so that the formation temperature can be estimated from the thermal decay curve. The ADARA tool is normally limited to shallower depths than the WSTP because of the requirement for softer formations for penetration. The greater penetration distance of this tool, however, means that the influence of the thermally disturbed region around the borehole is rarely seen.

\section{DOWNHOLE TEMPERATURE DATA}

\section{Line 745 Transect: Sites 859, 860, and 861}

Temperature data were collected at four sites $(859,860,861$, and 863 ) during Leg 141. Sites 861,860 , and 859 form an east-west transect of holes across the wedge along Line 745 (Figs. 1 and 3). Site 861 lies approximately $17.1 \mathrm{~km}$ east of the deformation front on Line 745 at a water depth of 1652 mbsl. The sub-bottom temperature profile is reasonably well constrained by ADARA and WSTP measurements, the deepest of which is at $228 \mathrm{mbsf}$ (Fig. 4A). Within the slight scatter of the data, the temperature profile is approximately linear below $20 \mathrm{mbsf}$ and has a gradient of $0.0538^{\circ} \mathrm{C} / \mathrm{m}$. The local bottom water temperature of $2.9 \pm 0.3^{\circ} \mathrm{C}$ was estimated by holding the different temperature tools in the drill string just above the sediment water interface. From Figure $4 \mathrm{~A}$ it can be seen that there may be a slight increase in temperature gradient somewhere in the top 20 mbsf of the sediment column. At Site 861 , the thermal conductivity data (Fig. 5A) show only a slight increase of conductivity with depth; therefore, the change in the near-surface temperature gradients observed at this site were not produced by changes in the sediment thermal conductivity with depth.

Site 860 is situated approximately $8.3 \mathrm{~km}$ east of the deformation front at a water depth of $2145.9 \mathrm{mbsl}$. The sub-bottom temperature profile is constrained by four ADARA measurements; the deepest successful measurement is, unfortunately, only at $58.4 \mathrm{mbsf}$ (Fig. 

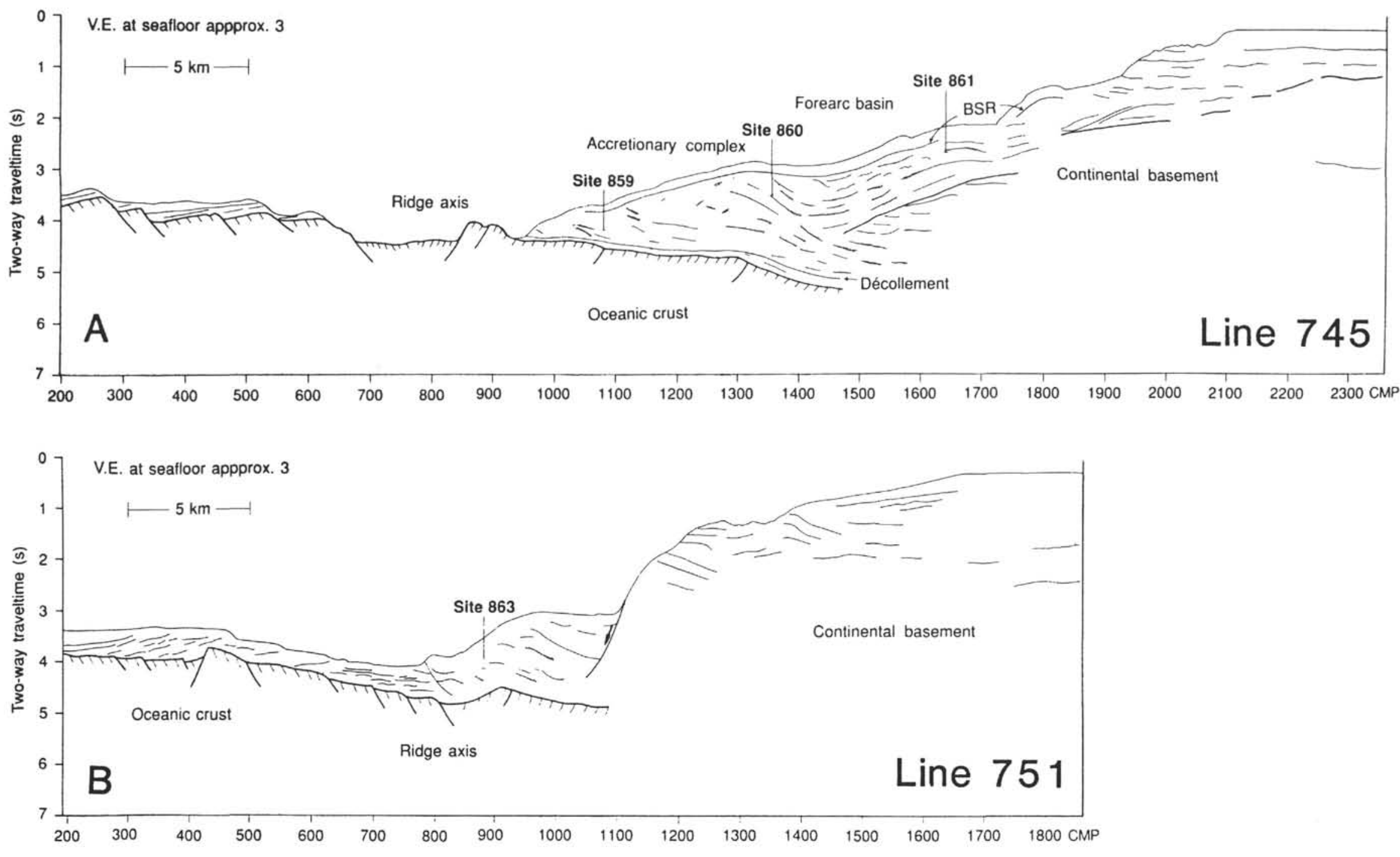

Figure 3. Line drawings of seismic reflection sections ( $\mathrm{A}=$ Line $745, \mathrm{~B}=$ Line 751 ) showing the position of the drill sites on the ODP Leg 141 transect (see Fig. 1 for locations) 
4B). Overall, within the scatter of the data, the temperature profile is reasonably linear in the top $58 \mathrm{mbsf}$ and has a gradient of $0.107^{\circ} \mathrm{C} / \mathrm{m}$.

Site 859 is located $3.2 \mathrm{~km}$ east of the deformation front and approximately $8 \mathrm{~km}$ east of the oceanic spreading axis at a water depth of $2741.2 \mathrm{mbsl}$. The measured temperature profile was not linear; sharp changes in temperature gradients occurred over short vertical distances (Fig. 4C). The salient features of this complicated temperature profile include the following: (1) the high temperature gradient of $0.288^{\circ} \mathrm{C} / \mathrm{m}$ in the top $49 \mathrm{mbsf}$, (2) the decrease in gradient to $\sim 0.040^{\circ} \mathrm{C} / \mathrm{m}$ in the range between 49 to $126 \mathrm{mbsf}$, (3) the apparent $2.5^{\circ} \mathrm{C}$ temperature inversion between 126 and $187 \mathrm{mbsf}$, and (4) the very rapid increase in temperature from $17.3^{\circ} \mathrm{C}$ at $187 \mathrm{mbsf}$ to over $55^{\circ} \mathrm{C}$ at $245 \mathrm{mbsf}$.

Tool disturbance and the potential penetration of borehole fill have degraded the quality of some points at Site 859 (Fig. 5). In general, poor quality data may be too cool, resulting from the influence of the cold borehole fluids and, thus, represent minimum temperatures. The best quality points are represented by a filled dot, slightly disturbed records are represented by a bracketed symbol, and the most disturbed measurements are represented with an open dot. A conservative temperature profile through the best quality points (Fig. 5) is represented in Figure 4C. Some of the bracketed points may, however, be quite reasonable representations of the formation temperature. For example, the measurement at $71.3 \mathrm{mbsf}$ shows the tool was probably disturbed after a period and penetrated the sediments a second time (Fig. 5). Fits to both decay profiles indicate, however, the same formation temperature to within $0.4^{\circ} \mathrm{C}$. This suggests the tool disturbance has not seriously effected the estimated formation temperature in this instance. Note that in the case of the reading at $245 \mathrm{mbsf}$, although the record shows considerable disturbance, the formation temperature must be at least $56^{\circ} \mathrm{C}$ (the continued thermal warming trend recorded just prior to tool extraction extrapolates to $\sim 61^{\circ} \mathrm{C}$, see the 859 Site chapter (in Behrmann, Lewis, Musgrave, et al., 1992).

The temperature profile at Site 859 is difficult to interpret with confidence. However, even if all the suspect temperature estimates are taken to represent only minimum formation temperatures, given the intervening distribution of good quality temperature determinations, the general form of the temperature profile still shows a highly complex form. Significantly, additional data provided by TLT borehole logging add an independent constraint on the residual complex form of the temperature profile characteristics at Site 859 that remain after drilling and associated fluid circulation has ceased. For the station data shown in Figure 6 the TLT was attached to the well seismic tool (WST) during vertical seismic profiling. The WSTP and TLT were held stationary in the hole for 10 to $15 \mathrm{~min}$. at each station. The TLT takes several tens of minutes to come close to equilibrium with the local surrounding borehole fluid. The WSTP stations allowed sufficient time to elapse so that a relatively accurate estimate (probably to within $\pm 0.5^{\circ} \mathrm{C}$ ) of the borehole fluid at the stations could be made from extrapolations of the thermal equilibration curves at each site (Site 859 chapter in Behrmann, Lewis, Musgrave, et al., 1992).

Many WST/TLT logging stations were attempted, these data overlap and fill in between the WSTPdata (Fig. 6). Comparison of the TLT logging data (which indicates temperatures after drilling) with WSTP data (measured before thermal drilling disturbance) shows that the relatively warm formations are cooler after pumping and drilling (Fig. 6) and this has smoothed the short wavelength temperature anomalies, such as the localized high-temperature-anomaly at 245 mbsf. However, even after disruption of formation temperatures by drilling and borehole circulation, the TLT station data indicate a high thermal gradient of at least $0.102^{\circ} \mathrm{C} / \mathrm{m}$ at this site. The TLT station results also confirm the localized warm-anomaly centered at $245 \mathrm{mbsf}$ indicated by the WSTP data. Logging temperatures indicate the local borehole fluid at $245 \mathrm{mbsf}$ is distinctly warmer (by $\sim 4^{\circ} \mathrm{C}$ ) than the regions immediately above and below. Significantly, remnants of the thermal inversion between 126 and 200 mbsf are also seen in the TLT station data (Fig. 6), with apparently a second cool zone between 248 and 289 mbsf. Thus, in the TLT station data the broad cool zone is almost symmetrically distributed around the more localized warm anomaly at 245 mbsf. After deconvolution, the other type of continuous TLT data (Sawyer et al., this volume) show the broad cool anomaly well, but suggest that it is mostly confined to the upper region between $\sim 150$ and 245 mbsf, with little evidence for the extension of the cool anomaly below $245 \mathrm{mbsf}$. The remnants of the localized warm anomaly at 245 mbsf were not observed in the continuous logs. The reasons for this are not clear. Perhaps its localized nature meant that the TLT passed by it too quickly for its signature to be picked up by the slow response of the tool.

\section{Site 863: Above the Triple Junction}

Site 863 is situated on Line 751 to the south of the main transect of holes on Line 745 . It lies $2.5 \mathrm{~km}$ east of the deformation front at a water depth of $2564.2 \mathrm{mbsl}$. The site lies directly over the spreading axis of the underthrust oceanic ridge. No BSR was identified locally at Site 863 . The sub-bottom temperature profile is relatively well constrained to depths of $245 \mathrm{mbsf}$ by six WSTP and three Adara measurements (Fig. 4D). The temperature profile is not linear. Several sharp changes in temperature gradient occur over short vertical distances. The changes in temperature gradients are best defined in the region between 0 and $85 \mathrm{mbsf}$, where there appears to be two peaks in temperature at approximately 25 and $65 \mathrm{mbsf}( \pm 10 \mathrm{~m})$, with an intervening temperature minima. In this upper region, the thermal conductivity data (Fig. 5C) indicate only a slight increase in conductivity with depth, although an apparent sharp increase in conductivity is seen across a diagenetic boundary close to $400 \mathrm{mbsf}$.

Good TLT downhole logging data were again obtained for this site from $230 \mathrm{mbsf}$ to the base of the hole at $700 \mathrm{mbsf}$. Two logging runs, well separated in time, were made at this site. The deconvolved TLT temperature data is presented in Sawyer, (this volume) and suggest that the portion of the temperature profile below $245 \mathrm{mbsf}$ again is not linear, with a significant break in slope at $\sim 400 \mathrm{mbsf}$. Using the two temperature profiles and the drilling and circulation history, Sawyer et al. (this volume) made an extrapolation for Sites 863 (following the method of Von Herzen and Scott, 1991) to estimate the equilibrium temperature profile of the borehole after it had warmed and come into equilibrium with the surrounding formations. A significant change in temperature gradient from $80^{\circ} \mathrm{C} / \mathrm{km}$ above $400 \mathrm{mbsf}$ to $180^{\circ} \mathrm{C} / \mathrm{km}$ below 400 mbsf can be clearly observed in the equilibrium curve derived from the TLT data.

\section{CALIBRATION OF THE TEMPERATURE AT THE BASE OF THE STABILITY FIELD OF METHANE HYDRATE}

The temperature data are well constrained near the BSR at Sites 859 and 861 . Site 859 also has a full suite of WST and downhole sonic logging data not available at Site 861. At Site 859, the sonic downhole measurements and vertical WST profiling (Bangs et al., 1993) confirms that the well developed seismic BSR at this site is at $97 \mathrm{mbsf}$ $\pm 1 \mathrm{~m}$. The BSR is associated with a low-velocity zone between 97 and 105 mbsf that probably contains at least $1 \%-2 \%$ "free gas" (lowdensity methane fluid) at the base of the gas hydrate layer. The resistivity log within the low-velocity interval also shows a corresponding increase in resistance (Fig. 7) that would be expected with free gas in the layer (Bangs and Brown, this volume). The interstitial pore water geochemistry observations provide further indirect confirmation that the BSR lies near the base of an interval containing gas hydrates. A marked 25\% freshening of the fluid is seen (Fig. 7) in the interval between 27 and $70 \mathrm{mbsf}$ and is consistent with the dissociation of methane hydrates during core recovery. Because the temperature profile at Site 859 is not linear, it is fortunate that a good quality WSTP temperature measurement was obtained at $98.5 \mathrm{mbsf}$. The WSTP measurement constrains the temperature at the BSR to be 

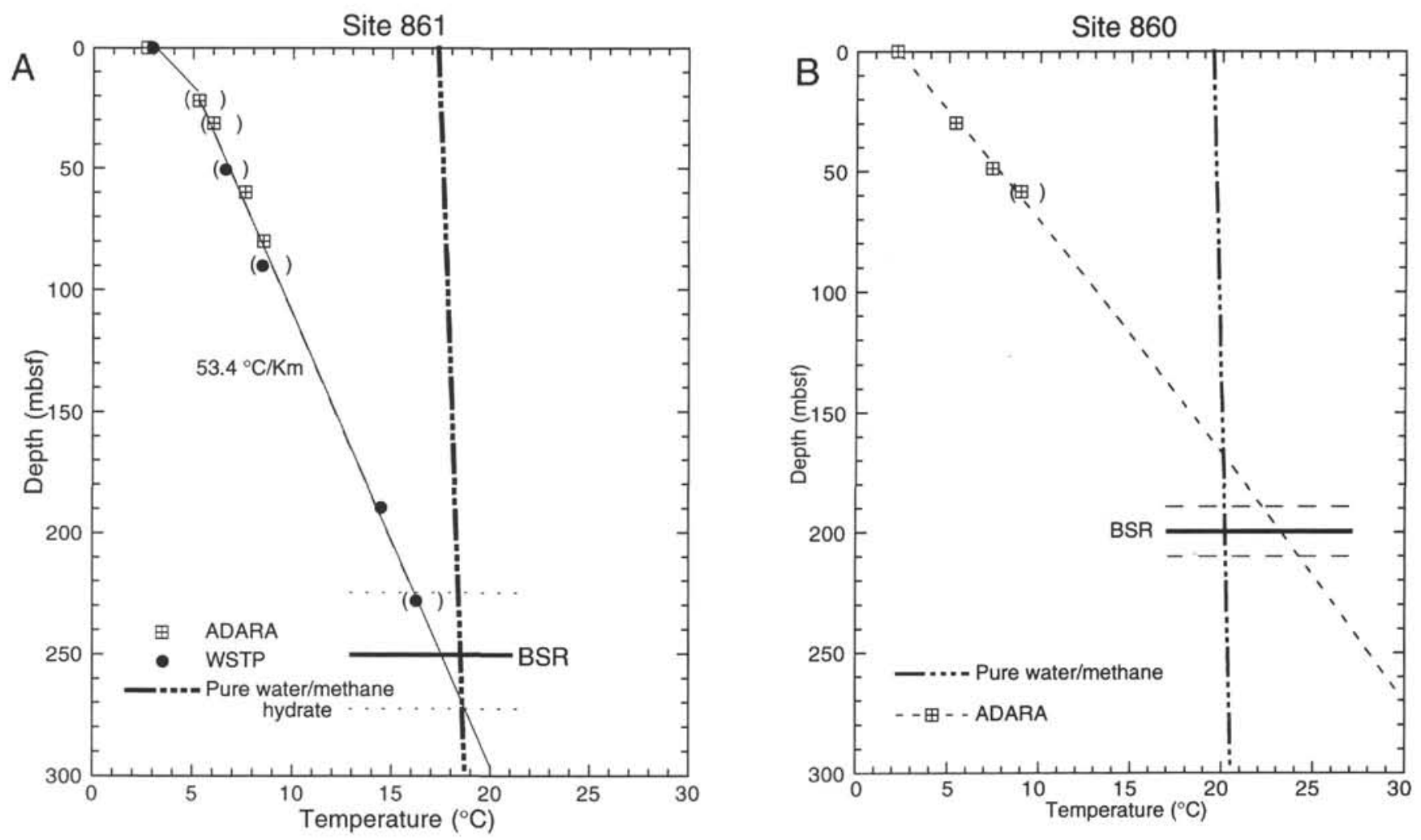

Figure 4. Leg 141 WSTP and Adara temperature data. A. Site 861 . B. Site 860 . C. Site 859 . D. Site 863 (see Figs. 1 and 13 for site locations). Good quality measurements are denoted with filled circles or boxes only, moderate quality measurements are denoted with bracketed symbols, and poor quality measurements are denoted with open circles. The temperature errors on the good quality points are considered to be $< \pm 0.25^{\circ} \mathrm{C}$.

$19.4^{\circ} \mathrm{C} \pm 0.2^{\circ} \mathrm{C}$ at a depth of $97 \mathrm{mbsf}(2838.2 \mathrm{mbsl})$ (Fig. 8). This calibration point plots $2^{\circ} \mathrm{C}$ lower than the pure water/methane hydrate stability boundary at $2838.2 \mathrm{mbsl}$, close to the estimated position of the seawater/methane curve (error bars are within the dimensions of the point on Fig. 8).

The constraint provided by the calibration at Site 861 is slightly less accurate than that at Site 859. The BSR, which locally occurs at $\sim 250 \mathrm{mbsf}$ in the region of Site 861 in seismic reflection sections, is a weak event. The linear temperature profile allows us to estimate the temperature at this depth accurately (Fig. 4A). The main error in this calibration is in defining the exact depth of the BSR because, unfortunately, there are no WST or downhole sonic velocity logs at this site. Bearing this limitation in mind, the temperature corresponding to the estimated $250 \mathrm{mbsf}$ depth of the BSR is $17.4^{\circ} \mathrm{C}$. If we assume the seismic velocity estimates could be $\pm 10 \%$ in error, the corresponding temperature error will be $\pm 1.3^{\circ} \mathrm{C}$ and the depth error will be $\pm 25 \mathrm{~m}$. The temperature of $17.4^{\circ} \mathrm{C} \pm 1.3^{\circ} \mathrm{C}$ at $250 \mathrm{mbsf} \pm 25 \mathrm{~m}(1902 \mathrm{mbsl} \pm$ $25 \mathrm{~m}$ ) lies at a lower temperature than the pure water/methane boundary (Fig. 8).

Thus, when compared with the previous estimates of Hyndman et al. (1992) we find that the results from Sites 859 and 861 generally plot at lower temperatures (Figs. 2 and 8 ) than the pure water/methane curve favored by Hyndman et al. They based their calibration of the temperature at the base of the hydrate stability field on ODP Site 808 (Nankai, Japan), DSDP Site 688 (Peru), and DSDP Sites 102/104 (Blake-Bahamas Outer Ridge). In each of these previous cases, variable amounts of critical data are missing and Hyndman had to estimate values for various parameters. At Site 808 in the Nankai accretionary wedge, good temperature data were available to well below the gas hydrate stability zone. However, there was no BSR at that site and the depth at which a BSR might form had to be laterally extrapolated from its nearest observed occurrence some 2 to $3 \mathrm{~km}$ arcward of the drill site. Heat flow at the toe of the Nankai accretionary wedge is not uniform so there is the potential for significant inaccuracy using a non-coincident location for the depth to the BSR. Blake-Bahama Site 533 is situated at 3191 mbsl. This calibration point is only based on three moderately good quality and one poor quality temperature measurements; there are also no downhole velocity logs, no thermal conductivity measurements, and the deepest temperature measurement was made at approximately $400 \mathrm{mbsf}$, well above the BSR at roughly $620 \mathrm{mbsf}$. This site represents a relatively poor quality P-T calibration point as a consequence. As a calibration point, Peru Hole 688A is also rated very poor for the following reasons: (1) There are no reasonable thermal conductivity data, (2) the temperature data are sparse and no measurements were made below $46 \mathrm{mbsf}$, and (3) there are no downhole logs to determine either the actual depth of the BSR or the sediment velocity. Based on an estimated velocity, Hyndman et al. (1992), suggest that the BSR occurs at approximately $450 \mathrm{mbsf}$. This means that the shallow temperature measurements have to be extrapolated from 46 o 450 mbsf in the absence of any thermal conductivity data. Given the lack of any significant constrain, the Peru site is not a useful calibration point and has not been plotted on Figure 8.

Problems also exist for using Site 860 in the Chile triple junction region as a calibration point. The BSR is well developed on seismic reflection sections in the region of Site 860 (Bangs et al., this volume). While sonic logging data between 70 and 160 mbsf (Bangs et al., 1993) do help constrain the seismic velocity in the upper part of the sedimentary section these data do not extend down to the BSR and the seismic velocity may be in error by as much as $\pm 5 \%$. Consequently, the true BSR depth may differ from the estimated depth at $200 \mathrm{mbsf}$ by $\sim \pm 10 \mathrm{~m}$. Geochemical data appear to support the $200 \mathrm{mbsf}$ level 

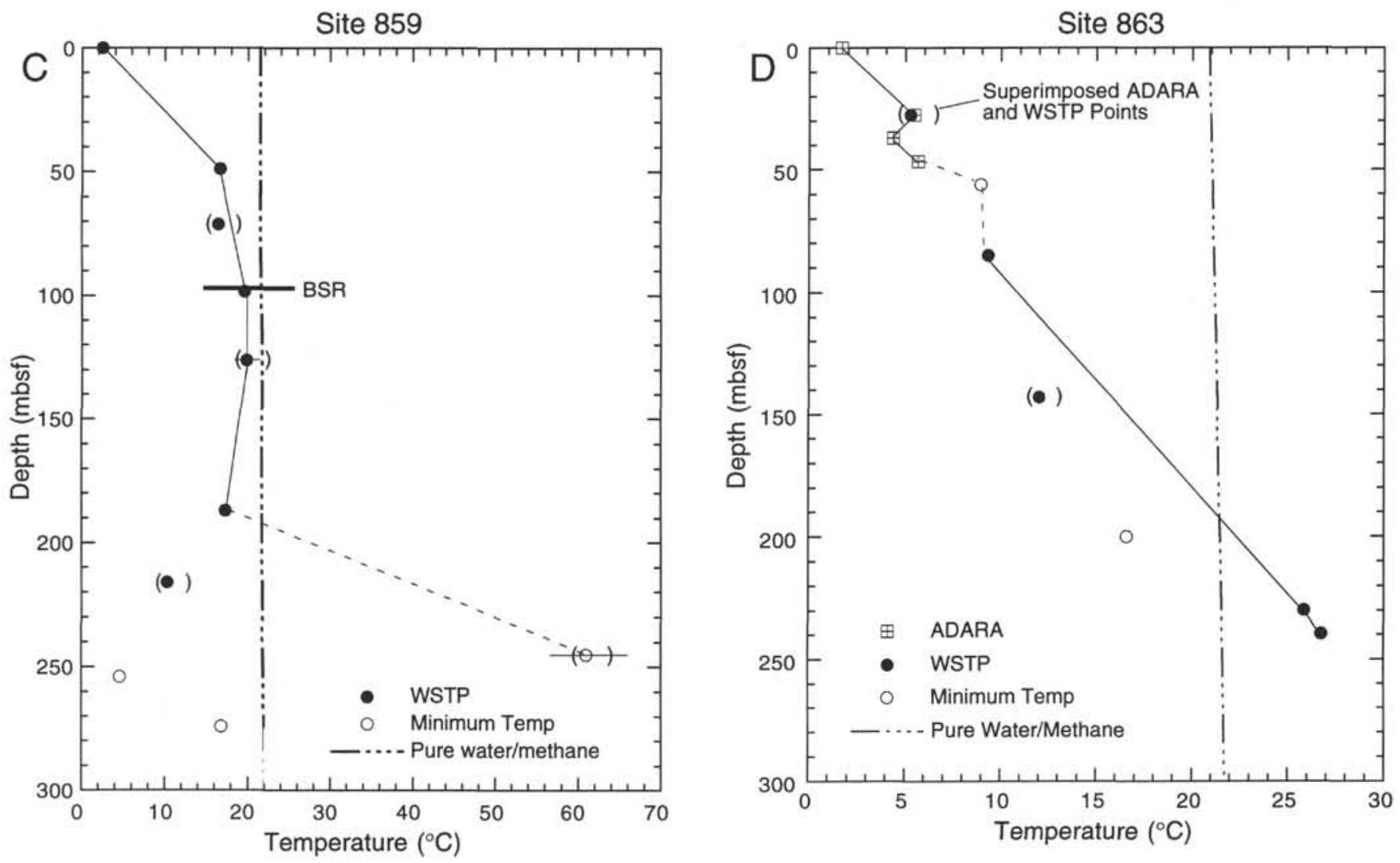

Figure 4 (continued).

for the base of gas hydrates at Site 860; anomalously low chlorinities were observed in the intervals between $\sim 100$ and $110 \mathrm{mbsf}$ and between 185 and 195 mbsf (Fig. 9). These anomalies are consistent with the freshening of fluids following dissociation of methane hydrates within local zones of high hydrate concentrations. Unfortunately, no temperature measurements were made below $58 \mathrm{mbsf}$ and so we have to extrapolate the shallow temperature profile downwards over a long vertical extent. The shallow temperature measurements suggest a relatively linear gradient of $0.113^{\circ} \mathrm{C} / \mathrm{m}$ at this site and the thermal conductivity data (Fig. 10B) shows a slight increase with depth. We can approximate the thermal conductivity by $k(z)=1.1154$ $+0.00090 z$, where $z$ is in meters (Fig. 10B). Using the determined thermal conductivity data and assuming a steady state conductive profile the temperature profile can be extrapolated downward using the following solution:

$$
T(z)=T_{0}+\frac{q}{0.0009} \ln \left(\frac{1.1154+0.0009 z}{1.1154}\right),
$$

where $\mathrm{q}$ is heat flow and $T$ is the surface temperature. When Equation 1 is used to extrapolate the temperature profile to greater depths, the resulting best-fit temperature extrapolation intersects the pure water/ methane hydrate stability curve at $166 \mathrm{mbsf}$ (curve shown in Fig. 4B). This is $36 \mathrm{~m}$ shallower than the $200 \mathrm{mbsf} \pm 10 \mathrm{~m}$ estimate for the BSR. Taking into account the potential error of $\pm 10 \mathrm{~m}$ in the depth to the BSR, the estimated calibration temperature at $200 \mathrm{mbsf}$ ( 2345.9 $\mathrm{mbsl}$ ) is $23.2^{\circ} \mathrm{C} \pm 1.0^{\circ} \mathrm{C}$. This plots above the pure water/methane stability boundary (Fig. 8). The presence of relatively high concentrations of $\mathrm{CO}_{2}$ (as much as $7 \%$ ) or a small percentage of high molecular weight hydrocarbons might have stabilized methane hydrates at higher temperatures (Fig. 2) and, thus, account for at least part of the discrepancy. Note, while these data may be better con- strained than the Peru data, we do not rate the quality of Site 860 as a BSR calibration point very highly. We simply lack the necessary temperature constraint to uniquely determine the temperature at the BSR. Relatively recent changes in bottom-water temperature, erosion, and fluid flow may all have easily caused a shallow deflection in the temperature profile.

In summary, Sites 859 and 861 provide the best calibration points of the P-T conditions at the BSR. Plotted on Figure 8 are all the various estimates for the in-situ stability field of natural methane hydrates obtained by drilling. Also plotted are the estimates of the stability field of pure-water methane provided by the compilation of Sloan (1989). The pure-water methane data on Figure 8 was fitted by the following equation:

$$
T_{z}=m_{3}+\left(m_{1} \log \frac{z}{1000}\right)-\left[m_{2} \log \left(\frac{z}{1000}\right)^{2}\right],
$$

where $T_{z}$ is temperature in ${ }^{\circ} \mathrm{C}$ at $z$ meters below sea level and $m_{1}, m_{2}$, and $m_{3}$ are fitting parameters that correspond to respective values of $20.334,2.296$, and 12.949. The same equation was used to fit the seawater-methane experimental data of Dickens and Quimby-Hunt (1994) and the calibration points provided by Sites 859 and 861 with the fitting parameters corresponding to values of $m_{1}=20.5, m_{2}=2.2$, and $m_{3}=11.66$. Essentially the curve through the seawater data and calibration points has the same general shape as the pure water/methane curve but falls $\sim 1.2^{\circ} \mathrm{C} \pm 0.1^{\circ} \mathrm{C}$ below it. We commonly refer to this as the estimated seawater/methane curve in our following discussions on the regional heat-flow patterns. All the poorer quality calibration points lie at higher temperatures. Note while we draw the readers attention to this fact, we are unsure with the current available data as to what this means in terms of possible calibration problems at these less well constrained sites vs. actual regional gas hydrate compositional variations at these widely distributed sites. 

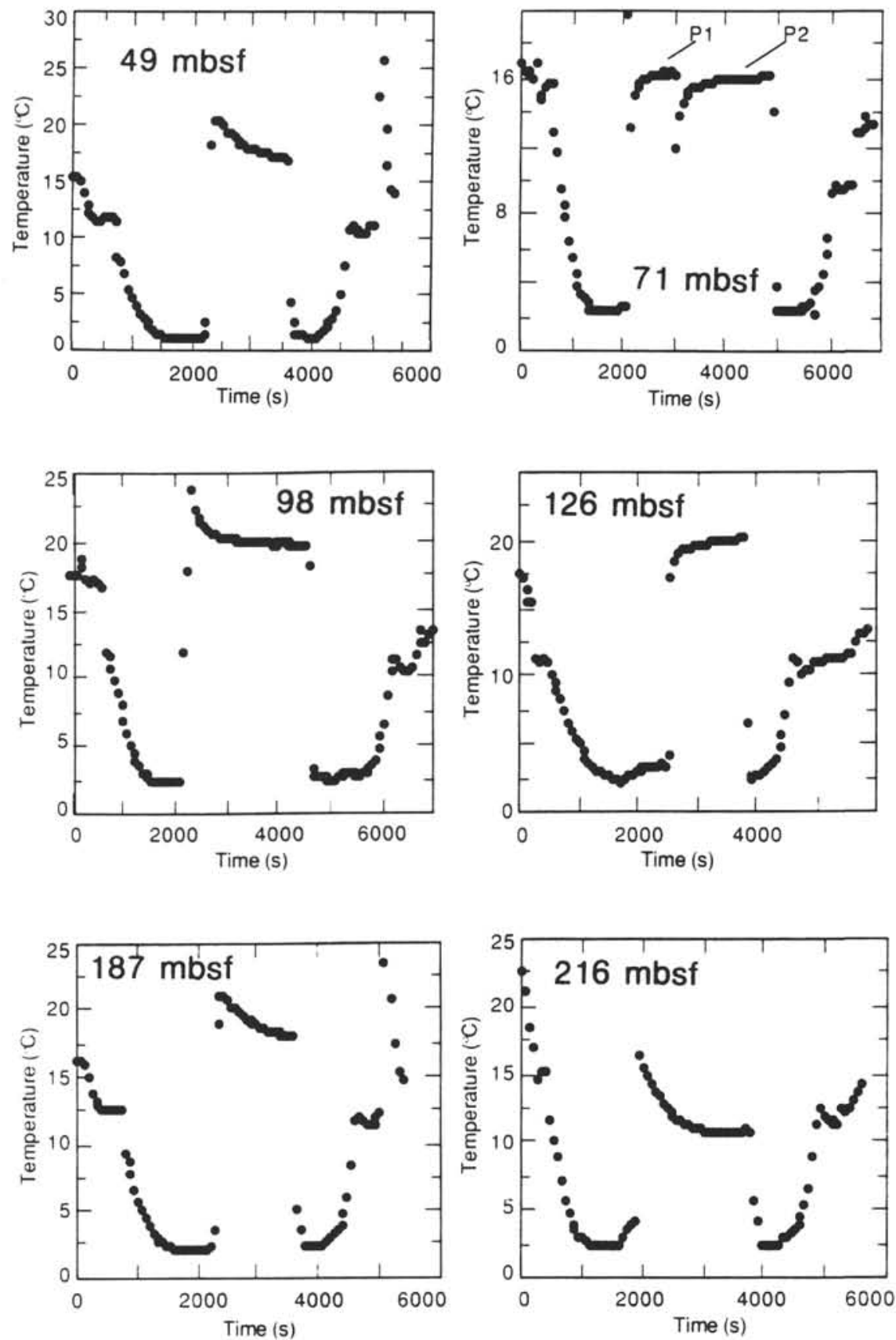

Figure 5. Thermal decay plots for WSTP measurements made at Site 859.
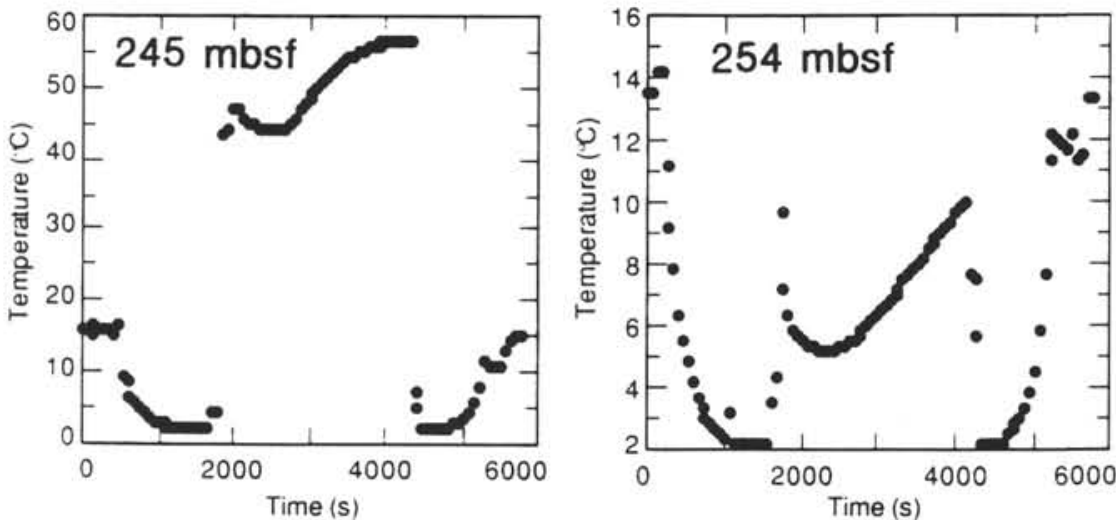
Site 859

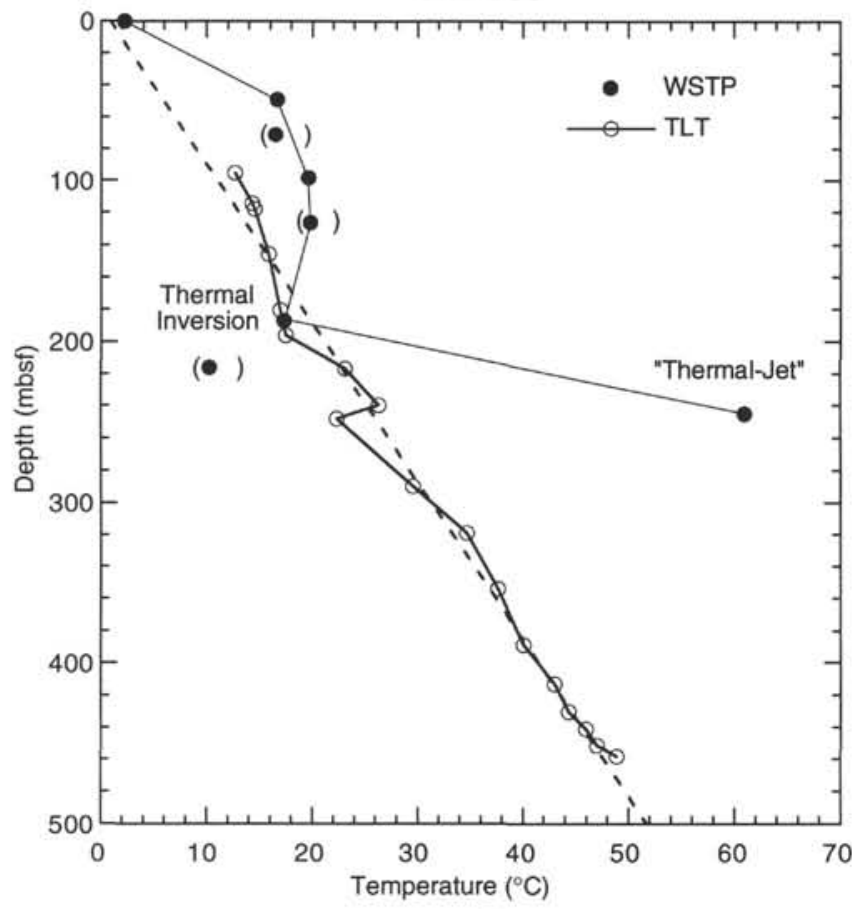

Figure 6. Comparison of TLT station data with the WSTP measurements at Site 859. The TLT tool was attached to the Schlumberger downhole logging string. It recorded the temperature of the borehole fluid and was run at the end of drilling. Cool seawater, circulated in the borehole during drilling, has disturbed the thermal regime in the sediments around the borehole before logging begins (Sawyer et al., this volume). At the time of logging these data borehole circulation has been stopped for over $24 \mathrm{hr}$ and temperatures within the borehole have begun to equilibrate with the surrounding formations. Normally, the previous circulation has resulted in cooling of the region around the borehole. Over a period of time the temperature begins to recover so that in successive logging runs there is a net warming of the borehole region. At Site 859 , the WSTP and TLT were held stationary in the hole for 10 to $15 \mathrm{~min}$ at each station. The TLT takes several tens of minutes to come close to equilibrium with the local surrounding borehole fluid. The WSTP stations allowed sufficient time to elapse that a relatively accurate estimate (probably to within $\pm 0.5^{\circ} \mathrm{C}$ ) of the borehole fluid at the stations could be made from extrapolations of the thermal equilibration curves at each site ("Site 859" chapter, Behrmann, Lewis, Musgrave, et al., 1992).

\section{CHANGING THERMAL REGIME ACROSS THE WEDGE: THE TRANSECT ALONG LINE 745}

The transect of holes along Line 745 (Figs. 1 and 3) characterizes the changing nature of the regional thermal regime across the accretionary wedge just prior to ridge subduction. Temperature gradients are lower and the profile is dominantly linear (Fig. 4) in the older regions of the wedge (i.e., Site 861 ), while high-temperature gradients and highly nonlinear profiles are found at the toe of the wedge (i.e., Sites 859 and 863 ). The major regional increase in the geothermal gradient toward the toe of the wedge is also clearly shown by the variation in depth to the BSR across the transect (Fig. 11). Were heat flow and thermal conductivity relatively uniform across the wedge, the BSR should deepen in the sedimentary section towards the accretionary toe because the greater water depth and ambient pressure near the toe shift the hydrate stability field deeper. Instead, seismic reflection observations show that the BSR shallows towards the toe (Fig. 11), which directly implies a substantial increase in heat flow.

The minimum relative increase in heat flow toward to the toe can be made using the BSR data if we assume that over much of the wedge

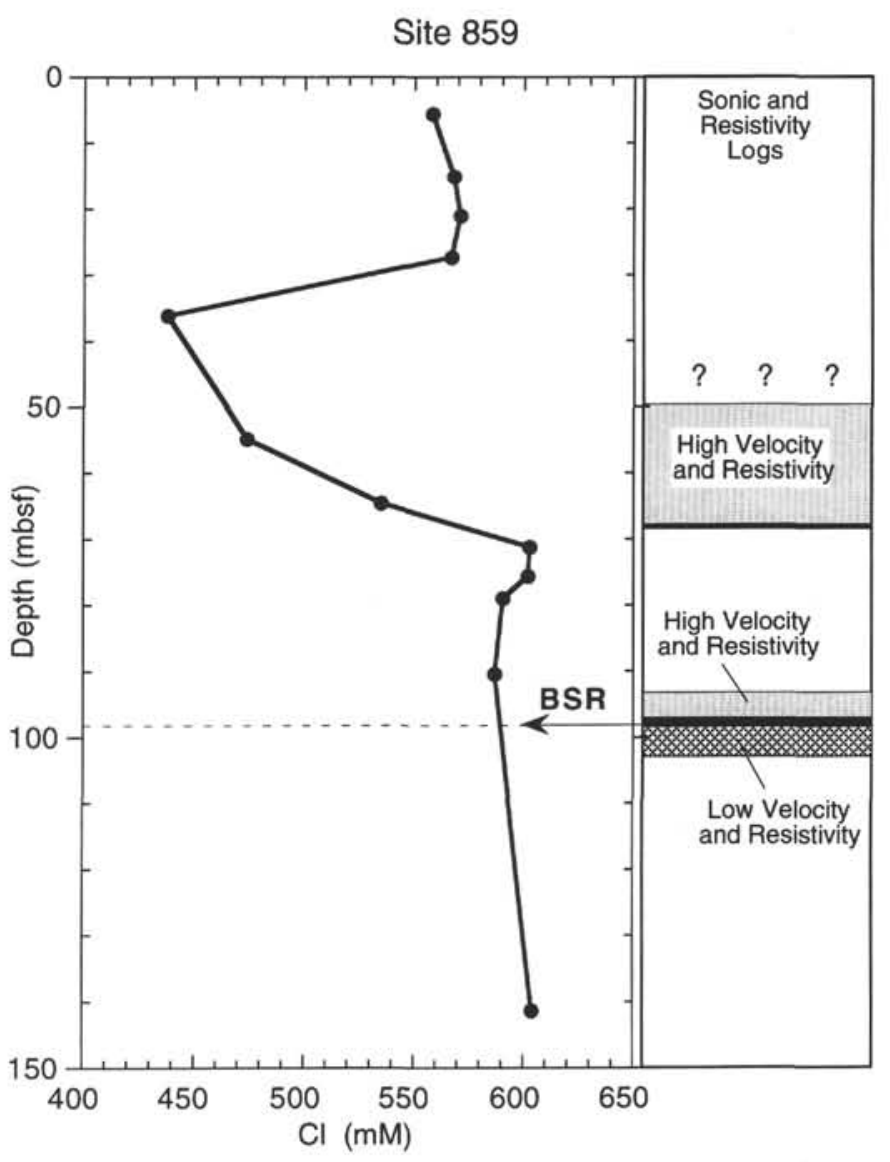

Figure 7. Chloride and resistivity data around the seismic BSR at Site 859.

heat flow was dominated by conduction and that recent erosion is generally limited. In Figure 11, we fit an average linear geothermal gradient that is constrained by two points, the bottom-water temperature across the transect which has been measured at the three ODP sites by holding the WSTP tool in the bottom water (all WSTP bottom water measurements lie close to $2.5^{\circ} \mathrm{C} \pm 0.3^{\circ} \mathrm{C}$ and there does not seem to be a consistent variation with water depth) and the temperature predicted at the BSR depth based on the estimated seawater curve (Eq. 2, $m_{1}=20.5, m_{2}=2.2$, and $m_{3}=11.66$ ). The depth to the BSR is obtained using the two-way traveltime to the BSR as seen on seismic reflection data together with the seawater velocity and the estimated seismic velocities in the sediments in the wedge. The shallow velocity structure in the wedge is extrapolated from the sonic logging and VSP data at Sites 859 and 860 (see Bangs and Brown, this volume). Note that true shallow average sonic velocities and, thus, depths could vary from the estimated values by as much as $5 \%$ to $10 \%$. As shown in Figure 11, based on the BSR data (Fig. 8), the average geothermal gradient in the top $100-200 \mathrm{~m}$ of the wedge increases by a factor of $\sim 2$ to 3 toward the toe of the wedge.

An average thermal conductivity for the sediments in the accretionary wedge must be assigned for a given region in the transect in order to estimate the changing average heat flow across the wedge based on the BSR data (Fig. 10). The thermal conductivity in the upper 100-250 mbsf of the wedge shows a small but consistent increase towards the accretionary toe (i.e., increases from Site 861 to Sites 860,859 , and 863 ). The intercepts of the best linear fits to the thermal conductivity data (Fig. 10) increase roughly linearly towards the toe, while the slopes increase quite rapidly between $17.1 \mathrm{~km}$ and $8.3 \mathrm{~km}$ and then are relatively uniform across the rest of the wedge. When assigning an average value for the thermal conductivity between the seafloor and the BSR depth for any given region in the 


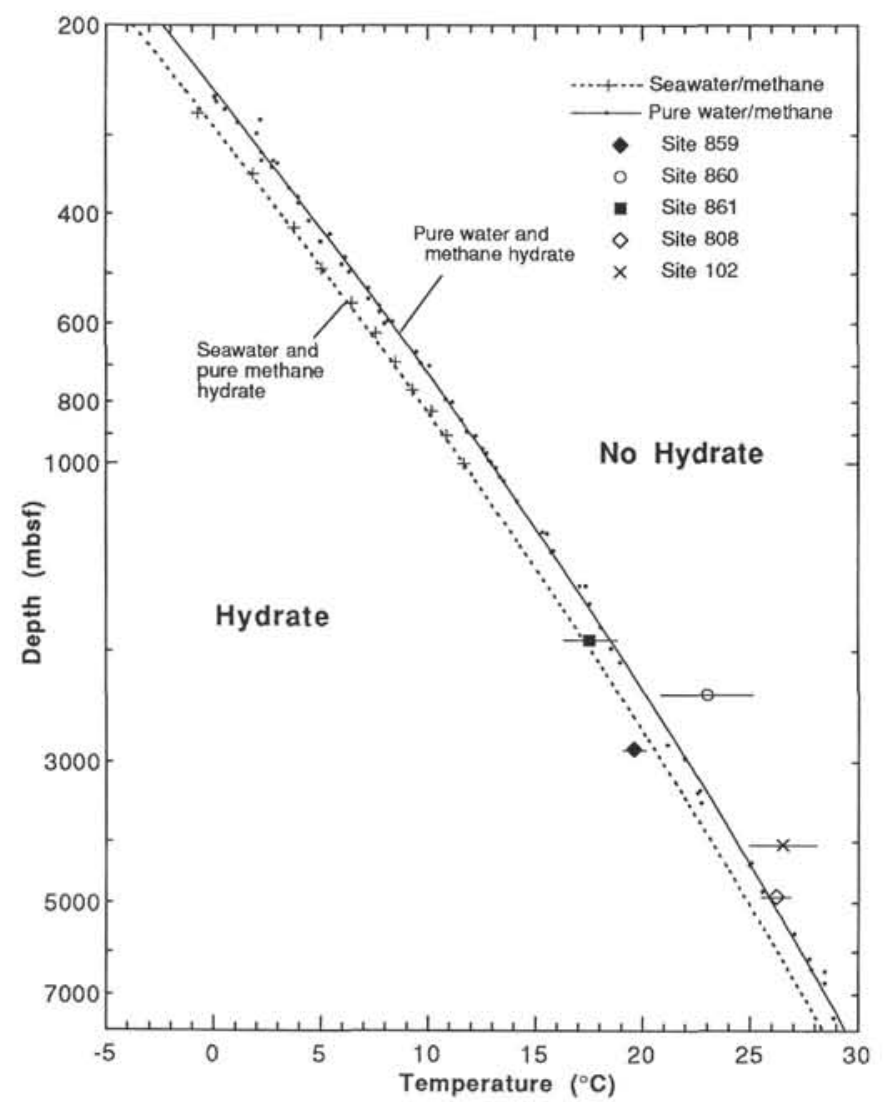

Figure 8. New calibration points for the depth and temperature conditions at the seismic BSR plotted vs. the experimental data (from Sloan, 1989) for pure water/methane hydrate (solid line and small circles). The seawater methane hydrate data is taken from Dickens and Quimby-Hunt (1994). The projection of the curve (dashed) through the best constrained calibration points at Sites 859,889 , and 892 is also shown. This curve projects along the estimated position of the seawater/methane hydrate stability curve (see Fig. 2). The depth can be related to in-situ hydrostatic pressure using the density of seawater $\left(1.035 \mathrm{~g} / \mathrm{cm}^{3}\right)$.

transect we have interpolated between the intercept and slope values obtained at each site.

The heat flow and geothermal gradients obtained from downhole measurements at Sites 859, 860, and 863 are shown in Figure 11, together with shallow seafloor heat flow probe measurements along the Line 745 transect. Due to the change in geothermal gradients in the upper 20 to $60 \mathrm{mbsf}$ (Fig. 4), the downhole data collected during Leg 141 have been used to define shallow and deep (>50 mbsf) geothermal gradients and corresponding heat flow values. For Site 859 , the shallow geothermal gradient of $0.288^{\circ} \mathrm{C} / \mathrm{m}$, that corresponds to a heat flow of $357.5 \mathrm{mWm}^{-2}$, was derived from WSTP measurements. The $>50$ mbsf geothermal and heatflow estimate is based on the equilibrium temperature profile derived from the TLT data (gradient $=\sim 0.108^{\circ} \mathrm{C} / \mathrm{m}$, heatflow $=\sim 131 \mathrm{mWm}^{-2}$ ) by Sawyer et al. (this volume). The TLT based estimated equilibrium profile at Site 859 is less sensitive to the effects of the thermally disturbed region around 200 to 245 mbsf that is probably associated with complex local fluid flow. At Site 860 , the shallow geothermal gradient is $0.107^{\circ} \mathrm{C} / \mathrm{m}$, and the corresponding heat flow is $119.30 \mathrm{mWm}^{-2}$. There are no temperature data below $60 \mathrm{mbsf}$ at this site. For Site 861 the geothermal gradient in the upper $20 \mathrm{mbsf}$ is $0.109^{\circ} \mathrm{C} / \mathrm{m}$ with a corresponding to a heat flow of $121.1 \mathrm{mWm}^{-2}$. This contrasts with the deeper gradient of $0.538^{\circ} \mathrm{C} / \mathrm{m}$ and corresponding heat flow of $62.4 \mathrm{mWm}^{-2}$ for the region below 60 mbsf.

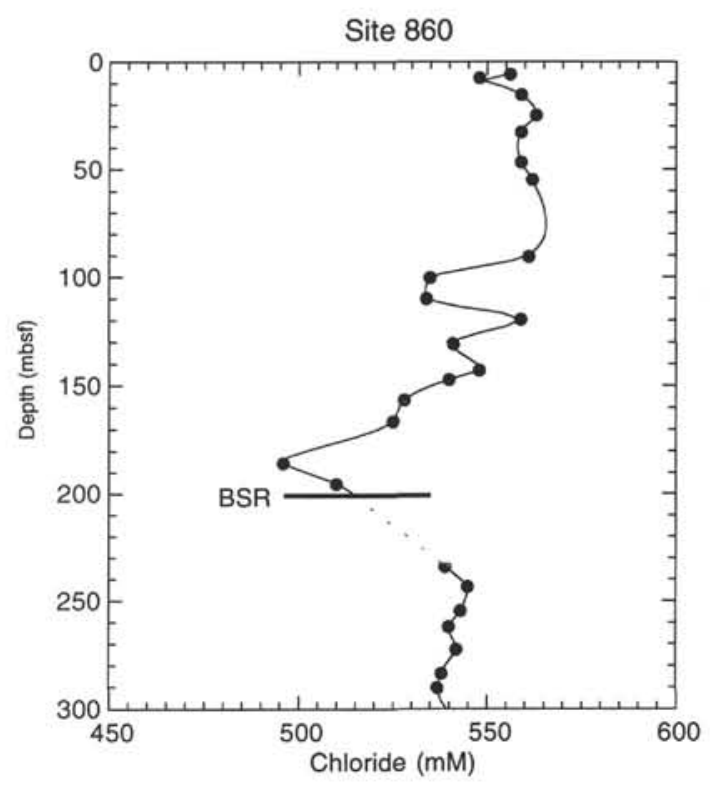

Figure 9. Chloride data at Site 860.

Figure 11 shows that the trends in shallow WSTP-derived temperature gradients and heat flow values are very similar to the seafloor probe measurements made by Cande et al. (1986). When both the shallow WSTP and seafloor probe data are used in conjunction it can be seen that the shallow temperature gradient and heat flow values substantially increase down across the slope toward the accretionary toe and then drops sharply just seaward of the wedge.

An important observation, based on a comparison between all of the different types of heat flow data, is the significant displacement in shallow geothermal gradients and heat flow to values above either the average BSR derived values or the values obtained from the deeper portion of the ODP boreholes. This discordance becomes particularly pronounced within $5 \mathrm{~km}$ of the deformation front where the maximum difference rapidly increases to $\sim 200 \mathrm{mWm}^{-2}$ between the shallow and deep conductive heat flow values. We shall return to address the probable hydrogeologic significance of this feature below.

The BSR-derived average geothermal gradient and heatflow does show a general but more subdued increase in gradient toward the accretionary toe (Fig. 11). No BSR was identified in front of the wedge. The smooth fit to the BSR-derived data agrees quite well to that obtained from the downhole ODP temperature measurements below $50 \mathrm{mbsf}$. If the local peak in the BSR thermal gradient and heat flow ( $\mathrm{d}$ on Fig. 11) is assumed to be a local anomaly produced by focused fluid flow, the underlying trend in the BSR derived geothermal gradient would fit the deep TLT-derived estimate of geothermal gradient at Site 859 more closely. Although we have constraints at Site 859 to show that the peak in estimated temperature gradient and heat flow at $d$ is in fact real, the same may not be the case for the other local departures in the BSR geothermal gradient from the smooth fit at a, b, and c on Figure 10. The departures at a, b, and c (and most the smaller departures) are probably related to errors in estimating the depth to the sea bed and underlying BSR due to surface roughness effects.

\section{DISCUSSION: FACTORS INFLUENCING THE REGIONAL THERMAL REGIME}

Heterogeneity is a characteristic feature of the regional heat flow patterns both along the strike and across the accretionary wedge in the $\mathrm{CTJ}$ region. A relatively widespread BSR associated with presence of gas hydrates is present through much the wedge in the CTJ region (Fig. 1) both north and south of the DFZ. Heat flow estimates based 
A

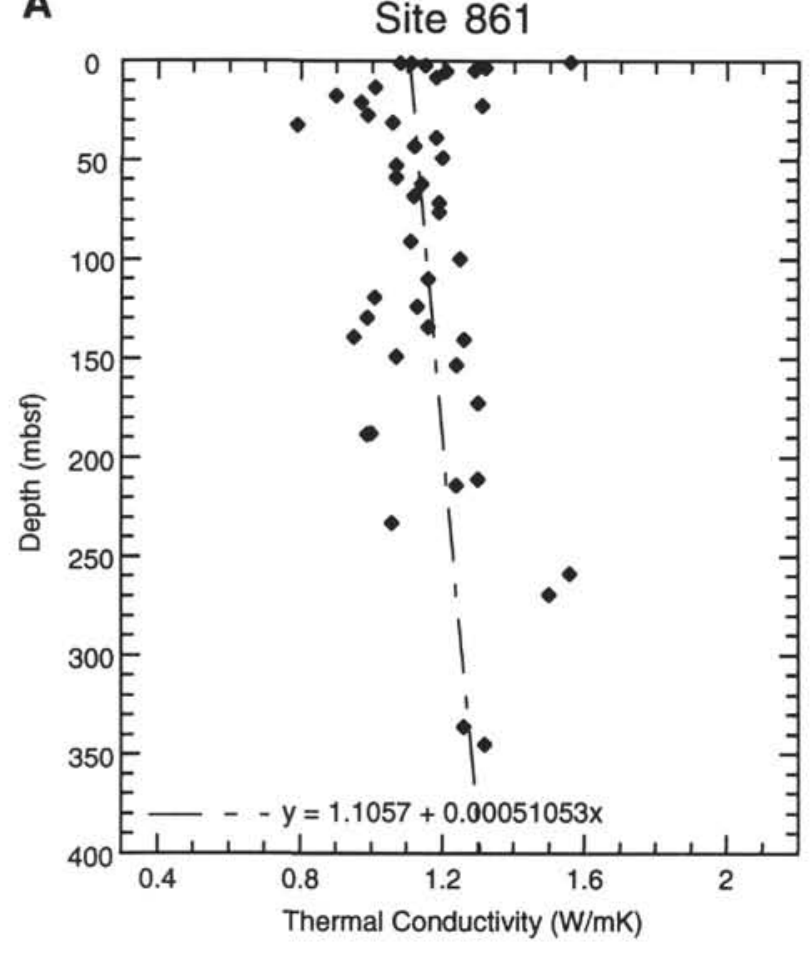

C

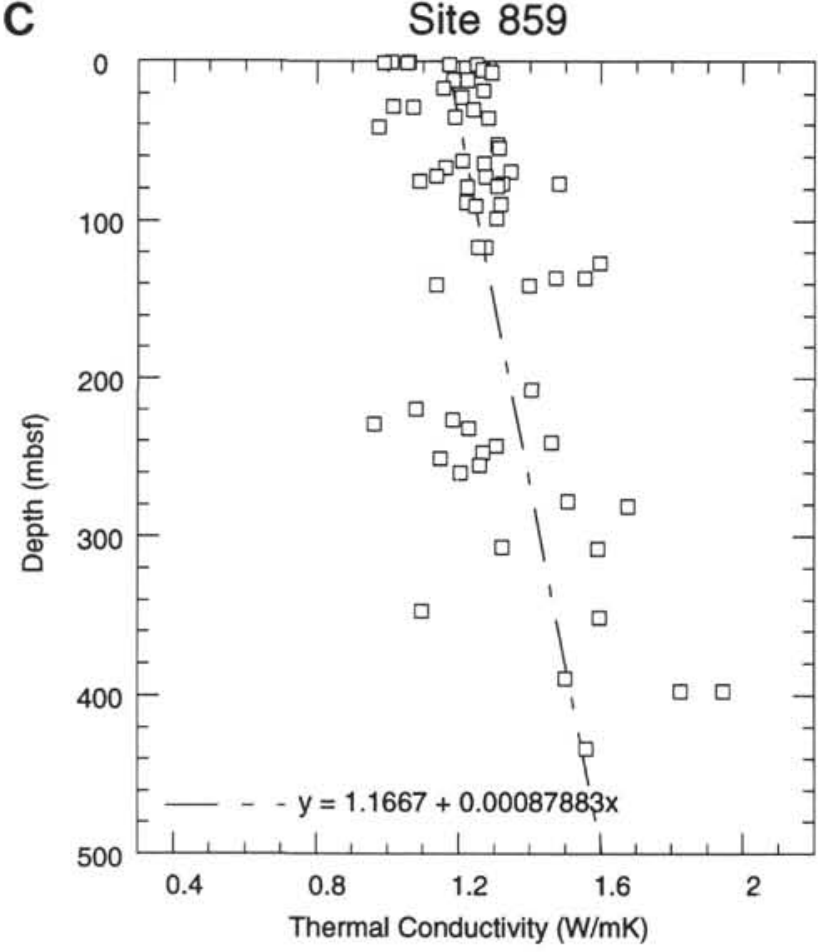

B

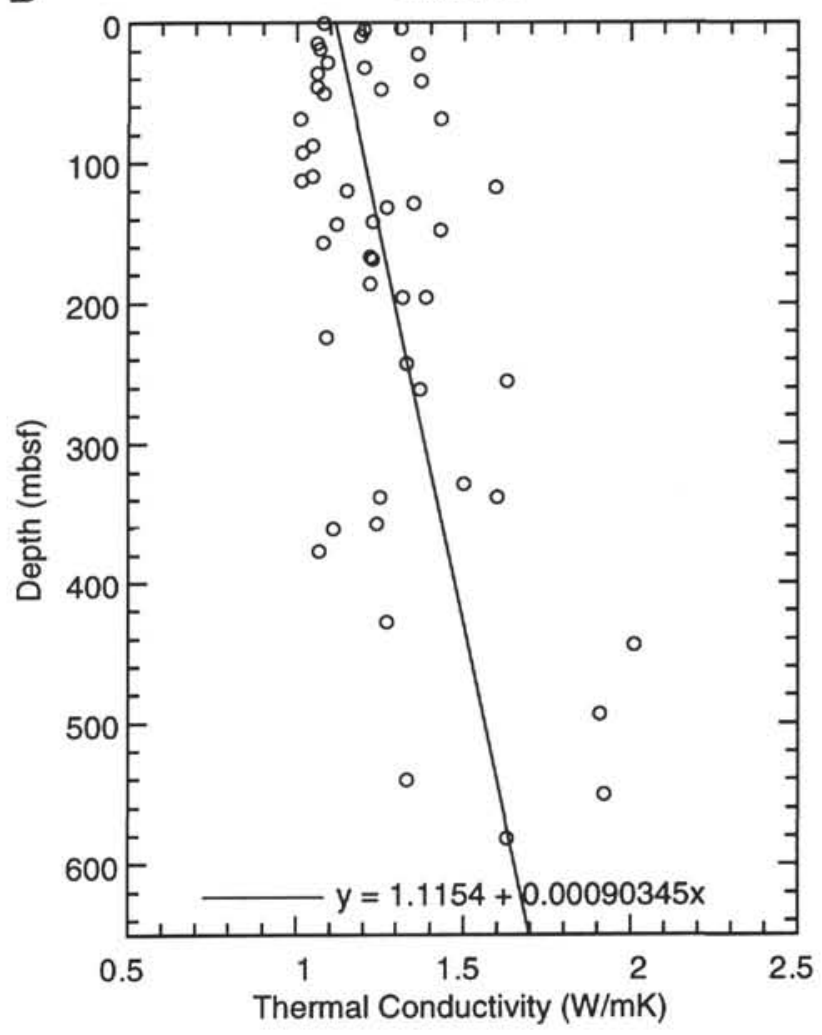

D

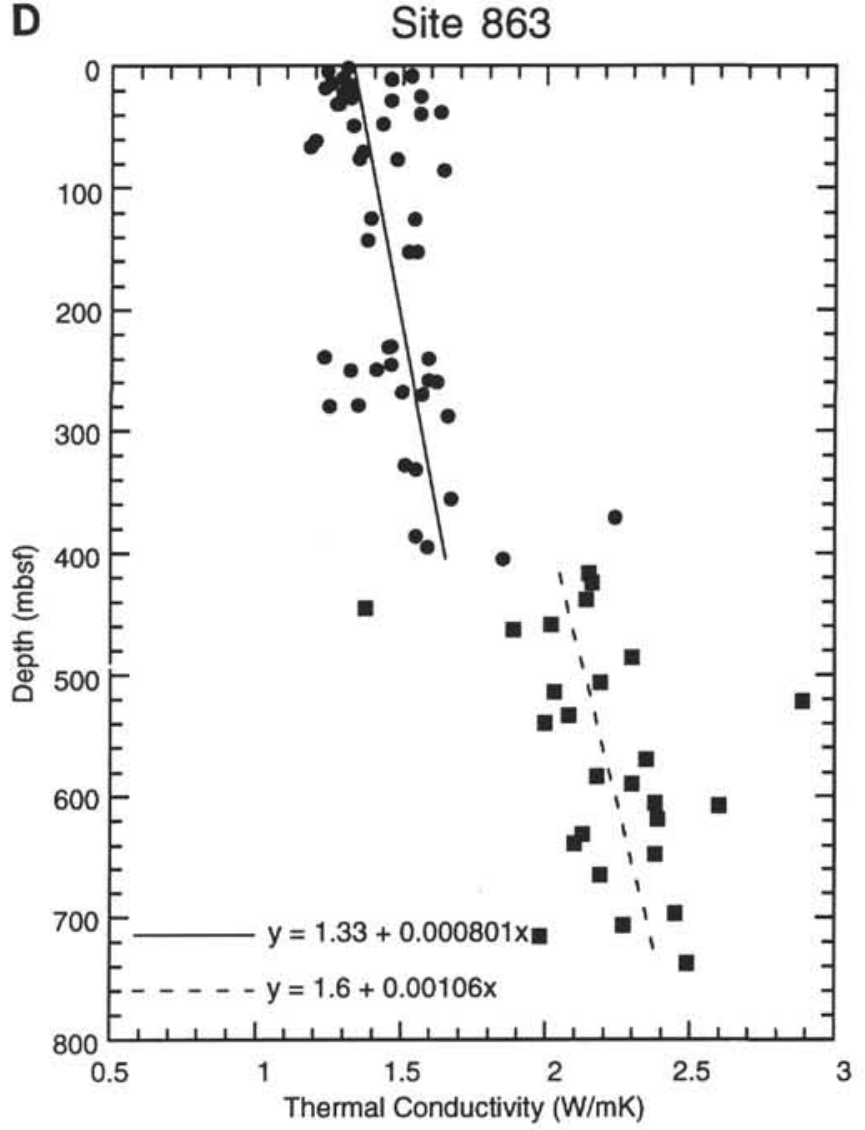

Site 860 
Figure 11. A. Geothermal gradient along Line 745 transect (see Fig. 1). B. Heat flow along Line 745 transect. Plotted are the seafloor probe measurements of Cande et al. (1987) collected in 1982, the shallow and deep geothermal gradients obtained from the Leg 141 boreholes, and the linear geothermal gradient obtained from the BSR and the estimated stability boundary for seawater/methane hydrate (shown in Fig. 8). The surface regions of the wedge are assumed to be hydrostatically pressured.

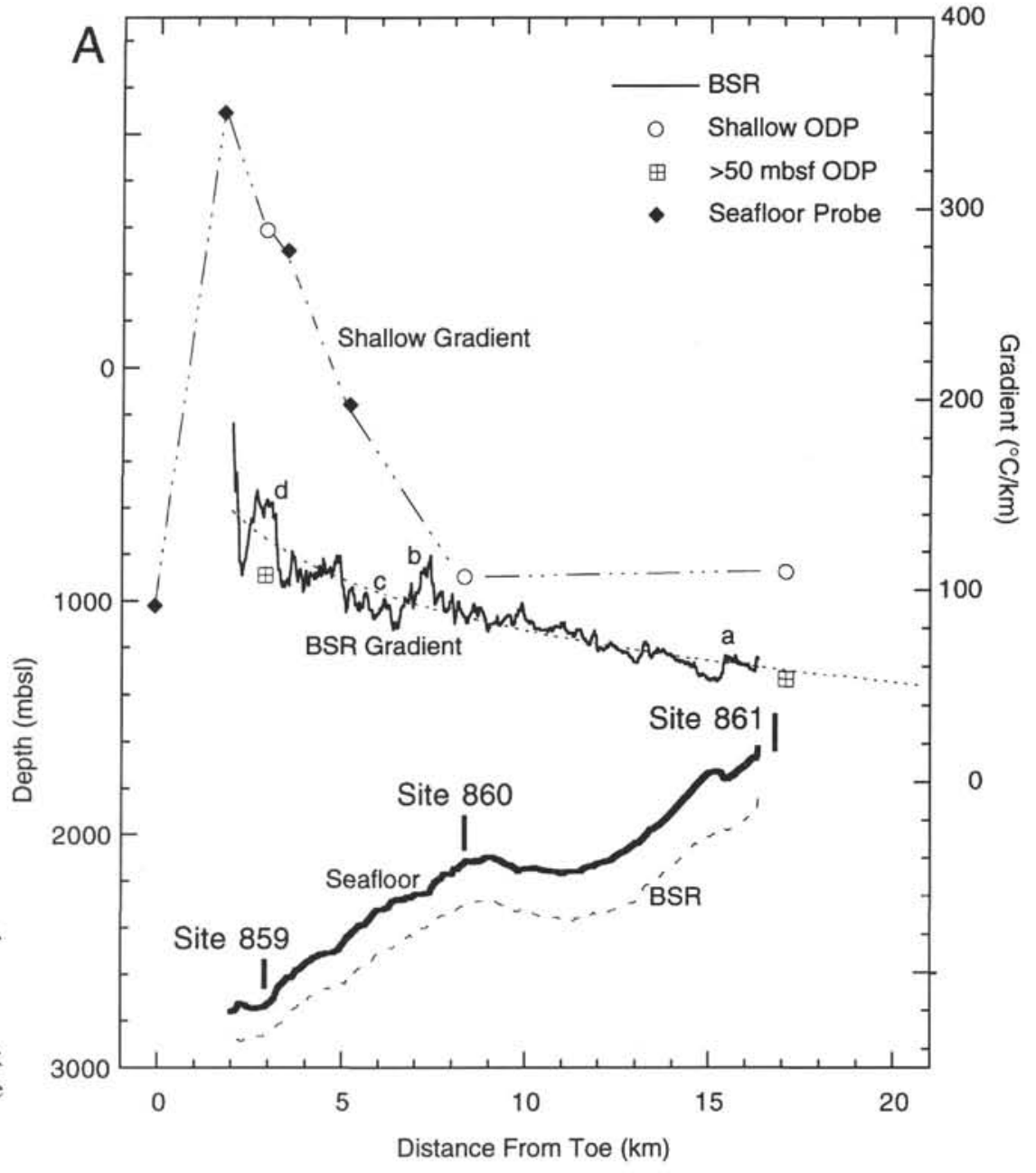

on the nature of the gas hydrate distribution enables us to extend some of the local observations based on seafloor probe and ODP borehole determinations to a regional scale. The BSR in the CTJ (Fig. 1) is associated with a negative seismic impedance contrast generated by a small amount of methane gas (see also Bangs et al., this volume) present in the sediment pores just beneath the level where the gas hydrate is stable. The close correlation of Sites 859 and 861 data to the extrapolated seawater curve (Fig. 8) of Dickens and QuimbyHunt (1994) allows the BSR data (Fig. 12) to be used to estimate the variation in regional heat flow patterns (see also Bangs and Brown, this volume).

To the north of the DFZ (Figs. 1 and 12) the spreading center axis is offset to the west and is approximately 3 Ma from being subducted. Unlike the southern region, heat flow estimated from the BSR distribution in the wedge to the north of the DFZ indicates a "relatively" uniform heat flow both along strike and across the wedge, with values mostly lying between $60-80 \mathrm{mWm}^{-2}$. In this northern region $\sim 5 \mathrm{Ma}$ old crust (Cande et al., 1987) is currently being underthrust beneath the toe of the wedge so that a generally high heat flow $\left(>250 \mathrm{mWm}^{-2}\right)$ is expected. Indeed, surface probe data from Cande et al. (1987) indicates that the heat flow is $>200 \mathrm{mWm}^{-2}$ in the region near the front of the wedge (Fig. 13). Seafloor probe data indicates, however, that heat flow rapidly decreases at the deformation front to a fairly uniform value of $\sim 60-80 \mathrm{mWm}^{-2}$ across much of the interior regions of the wedge (Fig. 13). In this region, seafloor probe and BSR data give approximately similar heat flow values so the shallow temperature gradient does not appear to change very much with depth in the top 100 to 300 mbsf. Linear temperature gradients are consistent with a predominantly conductive mechanism of heat transfer in the interior regions of the wedge.

The limited number of surface heat flow determinations made in the north of the DFZ along Line 2 (Fig. 13A, see also Fig. 1 for position) are broadly consistent with a conductive model where there is rapid thickening at the toe of the wedge, falling from $212 \mathrm{mWm}^{-2}$ in front of the wedge to $62 \mathrm{mWm}^{-2}$ near the toe, and then increasing again to $70-80 \mathrm{mWm}^{-2}$ further back in the wedge. In the absence of other effects, rapid tectonic thickening near the toe can disrupt the geothershallower ones. This can reduce the conductive geothermal gradient for a time by rapidly increasing the vertical thickness of the sedimentary pile and stretching the thermal contours (e.g., Ferguson et al., 1993). As the rate of thickening is reduced in the interior of the wedge the heat flow will recover as the temperature profile recovers. Unfortunately, we have little BSR evidence with which to further constrain the temperature distribution within a few kilometers of the toe of the wedge.

There is an abrupt change in the thermal regime across the DFZ (Fig. 12). South of the DFZ the processes controlling variations in the heat flow data along the transect across the wedge appear to be more erosion, and the effects of lateral fluid expulsion may all effect the observed patterns in regional heat flow in the wedge. Tectonic thickening can, however, be discounted as a mechanism for producing the observed temperature drop away from the accretionary toe because very little active accretion has been occurring at the toe of the wedge since Pleistocene times (Behrmann et al., this volume). Instead, sediments on the subducted plate appear to bypass the toe and become mal gradient by overthrusting deeper warmer sediments over cooler complex. Increasing proximity to the oceanic spreading axis, tectonic 


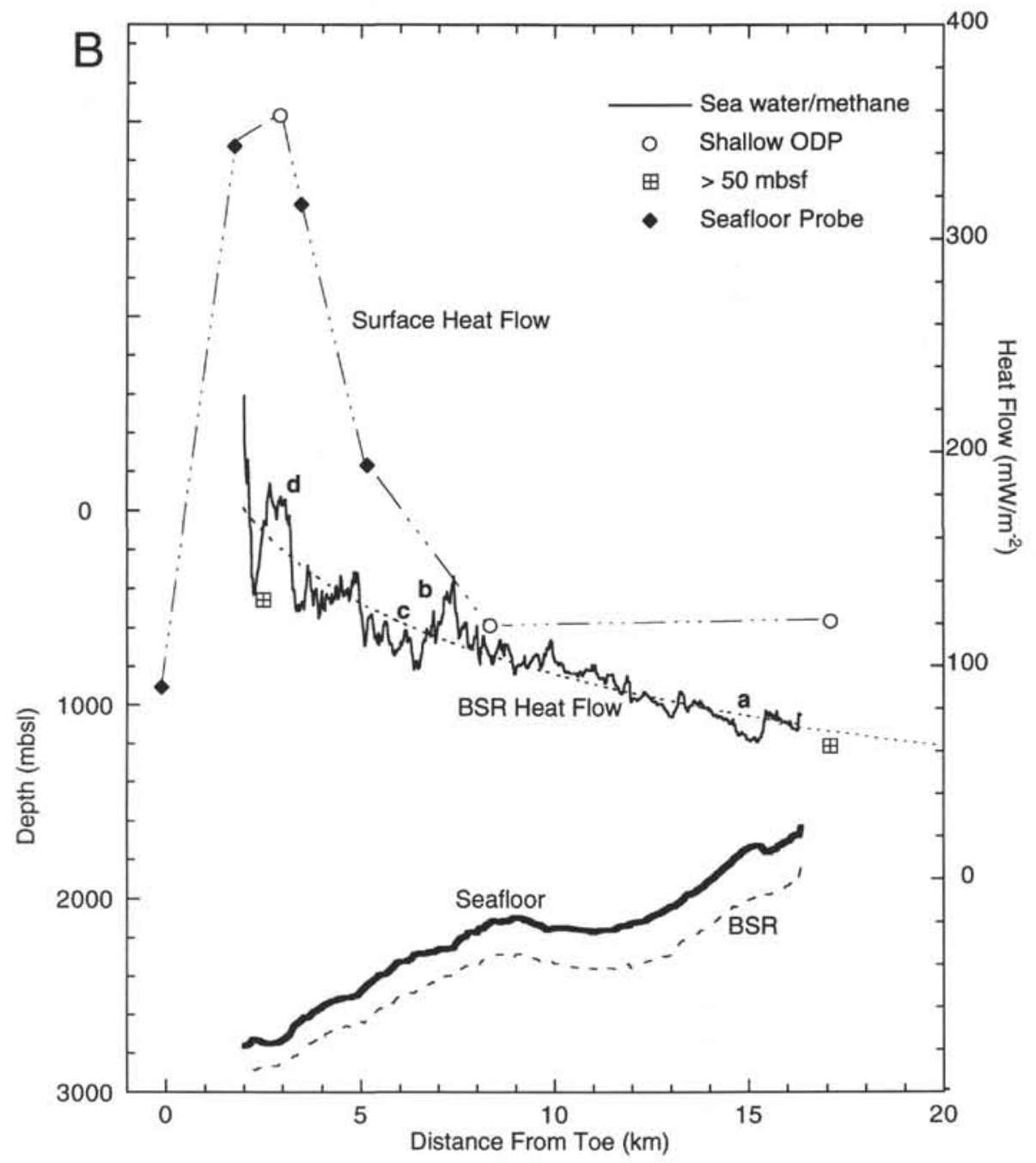

Figure 11 (continued).

thrust deep beneath the wedge (whether they are accreted at much deeper levels is not known).

The lateral variations in oceanic heat input related to proximity to the oceanic spreading axis and fluid flow are both considered likely to have exerted the greatest influence on the regional heat flow pattern. In Figure 14, we have plotted the estimated input of heat to the base of the wedge from conductive cooling of oceanic basement (Turcotte and Schubert, 1982), together with our heat flow data. The two curves generally have similar shapes and slopes and correlate well. The estimated input from the oceanic basement however, is approximately an order of magnitude higher than both the heat flow estimate based on the BSR and the data from the deeper regions of the boreholes. In other words, based on the conductive model we expect that $\sim 10$ times more heat was transferred from the oceanic crust to the base of the wedge than we measured. This discrepancy seems to be consistent across the accretionary complex.

In other ridge flank environments, the discrepancy between the estimated heat flow from conductive cooling of the oceanic crust and seafloor probe values has been attributed in previous studies to vigorous convective cooling of the oceanic basement by fluid circulation (e.g., Sclater et al., 1980). Seafloor probe measurements commonly record about half the expected heat flow in crust about $10 \mathrm{Ma}$ old. For a similar explanation to apply in the case of the Chile Triple junction region, fluid convection must have substantially cooled the oceanic crust within $5 \mathrm{~km}$ of the spreading axis (age of crust subducted at the accretionary front is probably less than $50 \mathrm{k} . \mathrm{y}$.) before the cooling oceanic crust was thrust beneath the toe of the accretionary wedge. Fluid convection is expected to diminish as the wedge is thrust over the spreading axis due to the generally low permeabilities and any overpressuring that accompanies tectonism and the loading of the deeper part of the sedimentary pile.

This brings us to the observation of the significant discordance between the shallow and deep heat flow estimates within $5 \mathrm{~km}$ of the toe of the wedge (Fig. 15). This discordance could relate to a strongly convex curvature to the shallow temperature profile that develops near the toe of the wedge. Indeed, the near-surface temperature profile at Site 859 shows an extremely large curvature in the near-surface regions and a highly complex morphology in the deeper regions. Together with the substantial anomalies in interstitial fluid geochemistry at both Sites 863 and 859 (Behrmann, Lewis, Musgrave, et al., 1992), it seems that the thermal regime within $5 \mathrm{~km}$ of the toe is strongly influenced by vigorous fluid flow (Fig. 15).

Interstitial fluid geochemistry suggests that a large component of the fluids at the levels of the thermal anomalies at Sites 859 and 863 have originated from deep within the wedge with the possibility of an additional strong oceanic basement influence (Behrmann, Lewis, Musgrave, et al., 1992). For example, at Site 863 the warm anomalies at 25 and 65 mbsf (Fig. 4D) are located near a series of faults and a region of sediment greatly enriched with $\mathrm{Fe}$ sulfide minerals. The sulfides are most prominent in the region between 0 and $65 \mathrm{mbsf}$. There are also large negative anomalies in $\mathrm{Ca}, \mathrm{Mg}, \mathrm{Sr}$, and total ionic strength between 56 and $75 \mathrm{mbsf}$, close to the deeper of the warm 
Figure 12. Regional heat flow distribution in the CTJ region based on the BSR distribution (Bangs and Brown, this volume) and the estimated stability boundary for seawater/ methane hydrate (shown in Fig. 8).

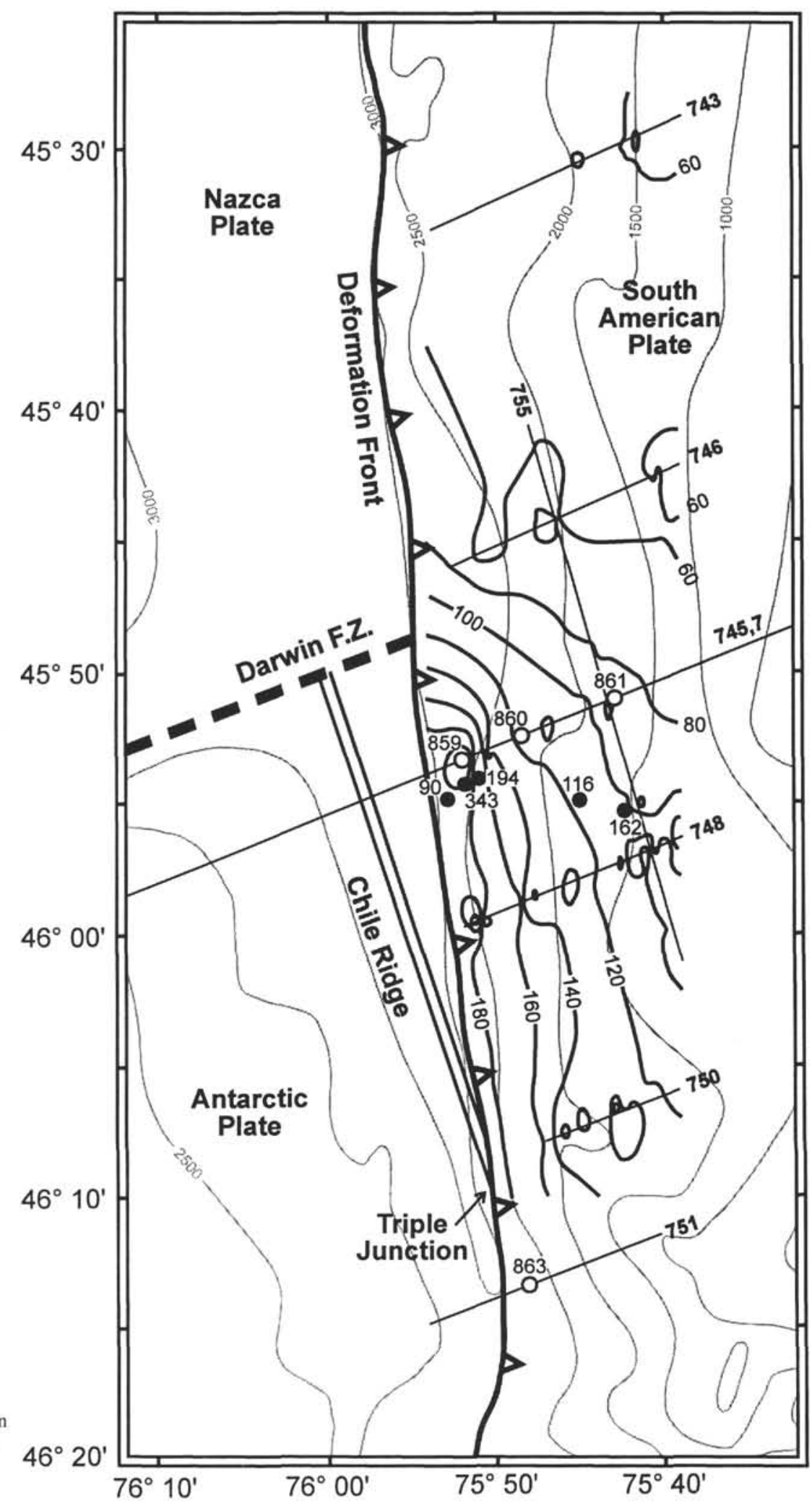

The focused release of geochemically anomalous warm fluids at the toe of the Chile accretionary wedge is highly consistent with observations at other accretionary wedges where active fluid flow has been observed (Moore et al., 1991). The hydrogeologic system in a wedge is driven by the expulsion of fluids via consolidation and mineral transformations that lead to overpressuring at depth. Large 
permeability anisotropies channel the expelled fluids laterally along faults and permeable sedimentary layers. What is unusual about the Chile Triple Junction region is the magnitude and complexity of the various temperature anomalies. The nature of the temperature anomalies at both Site 859 and 863 suggest a vigorous and transient system that changes character quickly. The changes may occur in response to episodic thermal influxes from the other parts of the wedge and from the oceanic crust. For example, the apparent thermal inversion between approximately 126 mbsf and 220 mbsf at Site 859 (Figs. 4 and 6) might relate to a basement-driven convective system having drawn cool-fluids laterally down into this part of the wedge. In contrast, the considerable gradient changes and high temperature of the thermal peak at 245 mbsf (Figs. 4 and 6) is consistent with recent and vigorous introduction of hot water flow along a narrow, high-permeability conduit. Spatially, the thermal-"jet" lies right at the proposed slope cover accretionary wedge contact zone (see chapter "Site 859" in Behrmann, Lewis, Musgrave, et al., 1992) in a region of no recovery between 235 and 245 mbsf.

The size and form of the temperature anomalies are different between Sites 859 and 863 at the toe of the wedge. This also indicates considerable lateral heterogeneity in fluid flow patterns at the toe. This heterogeneity limits the extent to which data collected in individual boreholes can be extended in three dimensions to give a regional estimate of the total heat transported by the moving fluids. Thus, while the BSR data in Figures 11 and 12 can be used to give a minimum estimate of the heat flow at the toe of the wedge, it is not clear what the upper limit of total heat flow (conduction plus advective) may be. It is quite possible that at least some of the "missing heat" that should have been input to the base of the wedge from the subducted oceanic basement has been transported laterally out of the system with the fluids and expelled at the toe of the accretionary wedge (Fig. 15).

The effects of the hydrogeologic regime in the accretionary wedge at the CTJ will be transposed on the expected exponential decrease in heat flow away from the oceanic spreading axis and any basement driven hydrothermal convection. If the observed heat flow related predominantly to the age of the crust beneath the prism, the heat flow contours on Figure 12 should run approximately parallel to the ridge axis and heat flow values should fall away from the ridge axis. We suggest that the effect of the transposition of the hydrogeologic regime in the wedge must be quite strong because, south of the DFZ, the heat flow contours trend parallel the trend of the accretionary front rather than the trend of the oceanic spreading axis (Fig. 12). Whether or not, however, the order of magnitude of the discrepancy in theoretical input and the observed values (Fig. 14) can be accounted for by this mechanism alone is not clear. We suspect that both initial cooling at the spreading axis by convection in the basement and removal of heat by lateral fluid expulsion in the wedge account together for the major discrepancy in the heat flux balance.

\section{CONCLUSIONS}

The following conclusions can be drawn from the heat flow data collected during ODP Leg 141:

1. The BSR calibration data obtained from ODP Leg 141 Sites 859 and 861 plot close to the estimated stability boundary of methane and seawater hydrate.

2. Heat flow determinations based on seafloor probe and ODP measurements and the regional estimates derived from the gas hydrate or BSR distribution suggest the heat flow increases in a nonlinear fashion toward the toe of the wedge.

3. The downhole temperature profiles are essentially linear (i.e., Site 861) in the interior of the wedge and are highly non-linear near the toe (i.e., Sites 859 and 863). Non-linearities in temperature commonly have corresponding pore fluid chemistry anomalies associated with them suggesting hydrogeologic processes are active at the toe.

4. The seafloor probe and heat flow determinations based on the shallow portions of the ODP holes give substantially higher heat flow

\section{HEAT FLOW $\left(\mathrm{mW} / \mathrm{m}^{2}\right)$}

A

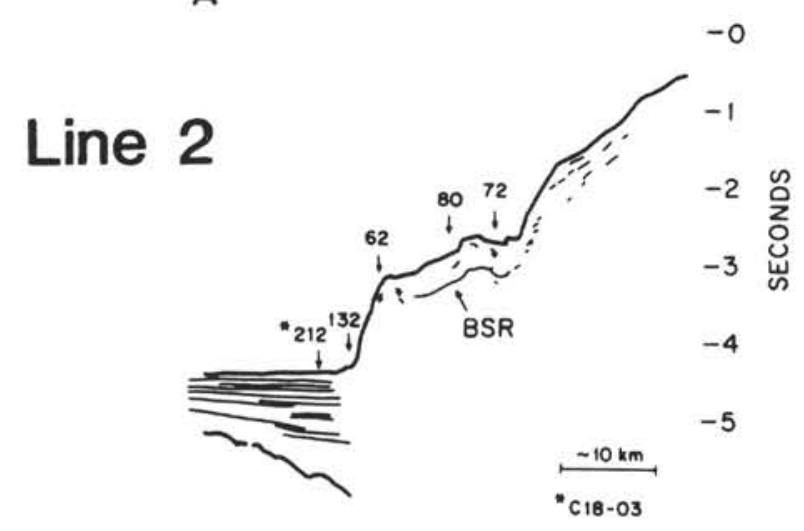

B

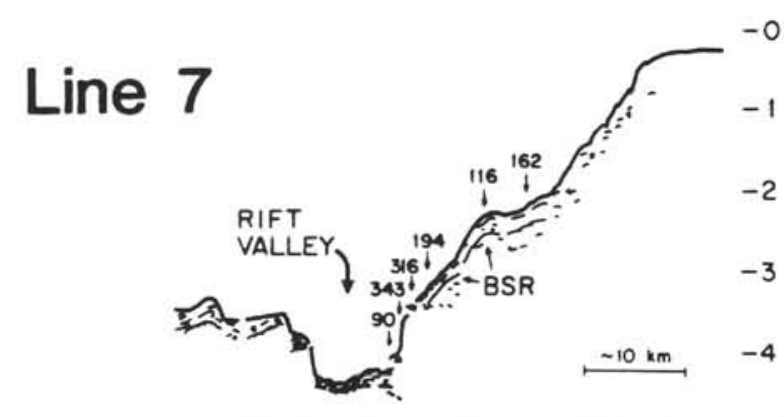

Figure 13. Line drawing of seismic Lines 2 (A) and Line 7 (B) showing surface heat flow and BSR distribution (Cande et al., 1987). Locations are shown on Figure 1 .

values within $5 \mathrm{~km}$ of the toe of the wedge than the values either obtained from the deeper parts of the ODP holes or the average values estimated from BSR distribution. This feature relates to greater degrees of hydrogeologic activity at the toe.

5. Near the toe, the hydrogeologic system is spatially heterogeneous, may be effected by both wedge and oceanic basement components, and appears to change episodically on a short time scale.

\section{ACKNOWLEDGMENTS}

The authors would like to thank John Sclater, Seiichi Nagihara, and Earl Davis for their helpful comments on this paper and the Shipboard Scientific Party, technicians and crew of Leg 141 for a productive and enjoyable cruise.

\section{REFERENCES}

Bangs, N.L.B., Sawyer, D.S., and Golovchenko, X., 1993. Free gas at the base of the gas hydrate zone in the vicinity of the Chile triple junction. Geology, 21:905-908.

Behrmann, J.H., Lewis, S.D., Musgrave, R.J., et al., 1992. Proc. ODP, Init. Repts., 141: College Station, TX (Ocean Drilling Program).

\footnotetext{
Abbreviations for names of organizations and publications in ODP reference lists follow the style given in Chemical Abstracts Service Source Index (published by American Chemical Society).
} 
Cande, S.C., Leslie, R.B., Parra, J.C., and Hobart, M., 1987. Interaction between the Chile Ridge and Chile Trench: geophysical and geothermal evidence. J. Geophys. Res., 92:495-520.

Carson, B., Suess, E., and Strasser, J.C., 1990. Fluid flow and mass flux determinations at vent sites on the Cascadia margin accretionary prism. $J$. Geophys. Res., 95:8891-8897.

Dickens, G.R., and Quimby-Hunt, M.S., 1994. Methane hydrate stability in seawater. Geophys. Res. Lett., 21:2115-2118.

Ferguson, I.J., Westbrook, G.K., Langseth, M.G., and Thomas, G.P., 1993. Heat flow and thermal models of the Barbados Ridge accretionary complex. J. Geophys. Res., 98:4121-4142.

Gieskes, J.M., Vrolijk, P., and Blanc, G., 1990. Hydrogeochemistry of the northern Barbados accretionary complex transect: Ocean Drilling Program Leg 110. J. Geophys. Res., 95:8809-8818.

Hyndman, R.D., Foucher, J.P., Yamano, M., Fisher, A., Berner, U., Brückmann, W., Byrne, T., Chabernaud, T., Firth, J.V., Gamo, T., Gieskes, J.M., Hill, I.A., Karig, D.E., Kastner, M., Kato, Y., Lallemand, S., Lau, R., Maltman, A.J., Moore, G.F., Moran, K., Olafsson, G., Owens, W.H., Pickering, K., Siena, F., Taira, A., Taylor, E.. Underwood, M.B., Wilkinson, C., and Zhang, J., 1992. Deep sea bottom-simulating-reflectors: calibration of the base of the hydrate stability field as used for heat flow estimates. Earth Planet. Sci. Lett., 109:289-301.

Kvenvolden, K.A., 1985. Comparison of marine gas hydrates in sediments of an active and passive margin. Mar. Pet. Geol., 2:65-71.
Kvenvolden, K.A., and Barnard, L.A., 1982. Hydrates of natural gas in continental margins. In Watkins, J.S., and Drake, C.L. (Eds.), Studies in Continental Margin Geology. AAPG Mem., 34:631-640.

Moore, J.C., Brown, K.M., Horath, F., Cochrane, G., MacKay, M., and Moore, G., 1991. Plumbing accretionary prisms: effects of permeability variations. Philos. Trans. R. Soc, London A, 335:275-288.

Sclater, J.G., Jaupart, C., and Galson, D., 1980. The heat flow through oceanic and continental crust and the heat loss of the Earth. Rev. Geophys. Space Phys., 18:269-311.

Sloan, E.D., 1990. Clathrate Hydrates of Natural Gasses: New York (Marcel Dekker).

Turcotte, D.L., and Schubert, G., 1982. Geodynamics: Applications of Continuum Physics to Geological Problems: New York (Wiley).

Von Herzen, R.P., and Scott, J.H., 1991. Thermal modeling for Hole 735B. In Von Herzen, R.P., Robinson, P.T., et al., Proc. ODP, Sci. Results, 118: College Station, TX (Ocean Drilling Program), 349-356.

Westbrook, G.K., Carson, B., Musgrave, R.J., et al., 1994. Proc. ODP, Init. Repts., 146 (Pt. 1): College Station, TX (Ocean Drilling Program).

Date of initial receipt: 28 September 1993

Date of acceptance: 4 October 1994

Ms 141SR-027

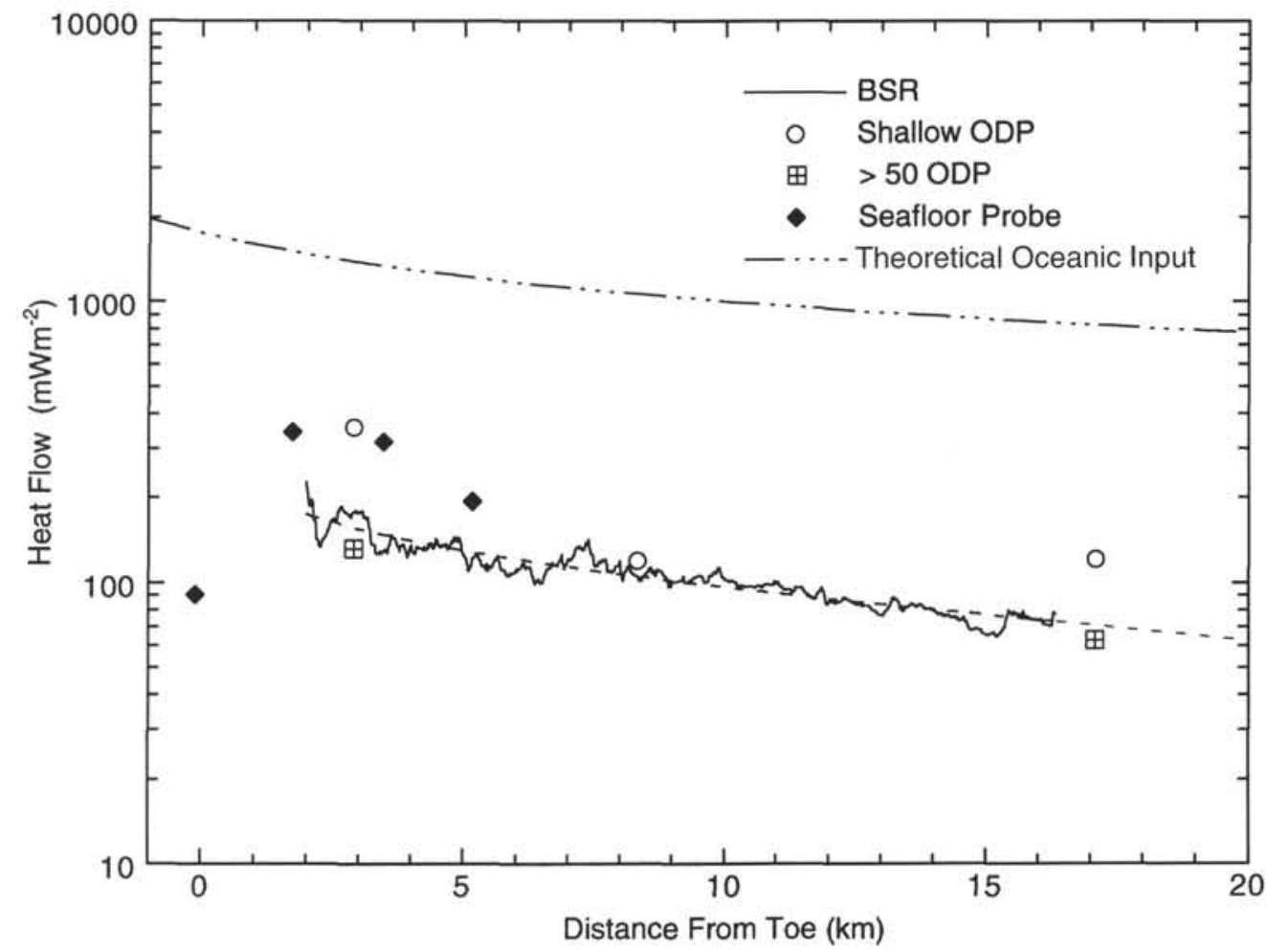

Figure 14. Comparison between the heat flow input from the conductively cooling oceanic basement (Sclater et al., 1980) below the wedge and the heat flow determined for the regions near the surface of the wedge. 


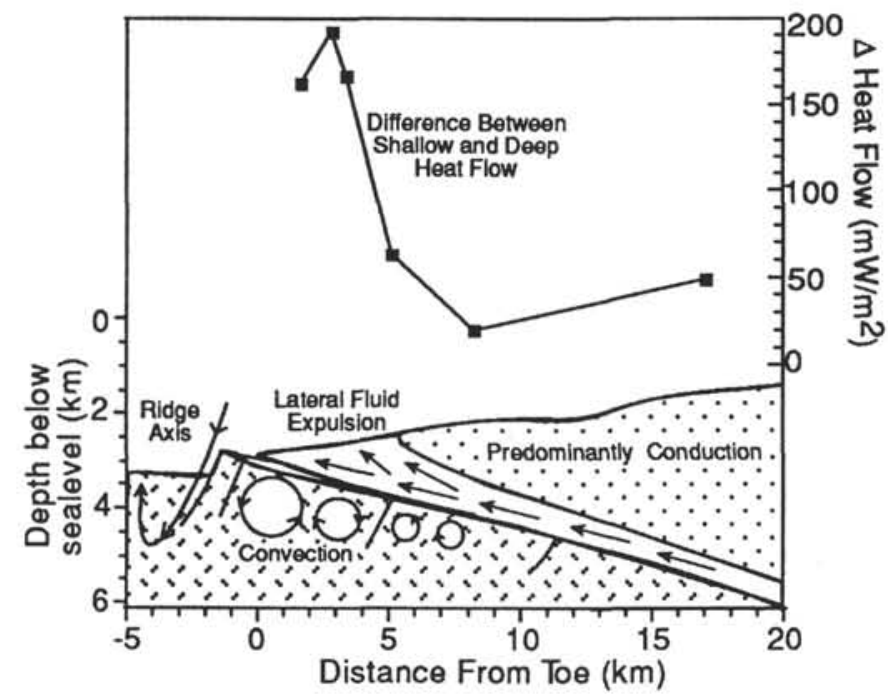

Figure 15. Schematic illustration of the basic model we propose explains the heat flow patterns seen in the Line 745 transect region. Heat transfer is predominantly by conduction in the "older" upper regions of the wedge. Conduction gives way to a complex transient hydrogeologic system that transfers much of the heat by fluid flow within $5 \mathrm{~km}$ of the toe. Also shown is the difference between the heat flow values obtained from the surface probe measurements and deeper measurements characterized by the heat flow estimated from the BSR at the same position in the wedge (see also Fig. 10). Note the very large discrepancy at the toe of the wedge that is qualitatively attributed to complex patterns of lateral fluid flow and expulsion. 